\title{
Review Article \\ Update on the Mechanisms of Pulmonary Inflammation and Oxidative Imbalance Induced by Exercise
}

\author{
O. F. Araneda, ${ }^{1}$ T. Carbonell, ${ }^{2}$ and M. Tuesta ${ }^{2,3}$ \\ ${ }^{1}$ Laboratorio Integrativo de Biomecánica y Fisiología del Esfuerzo (LIBFE), Escuela de Kinesiología, Facultad de Medicina, \\ Universidad de los Andes, Monseñor Álvaro del Portillo 12455, Las Condes, 7620001 Santiago, Chile \\ ${ }^{2}$ Facultad de Biología, Laboratorio de Fisiología e Inmunología, Universidad de Barcelona, Avenida Diagonal 643, \\ 08028 Barcelona, Spain \\ ${ }^{3}$ UDA Ciencias de la Salud, Facultad de Medicina, Pontificia Universidad Católica de Chile, Avenida Vicuña Mackenna 4860, \\ Macul, 7820436 Santiago, Chile
}

Correspondence should be addressed to O. F. Araneda; ofaraneda@miuandes.cl

Received 26 July 2015; Revised 2 November 2015; Accepted 8 November 2015

Academic Editor: Geraint D. Florida-James

Copyright (C) 2016 O. F. Araneda et al. This is an open access article distributed under the Creative Commons Attribution License, which permits unrestricted use, distribution, and reproduction in any medium, provided the original work is properly cited.

\begin{abstract}
The mechanisms involved in the generation of oxidative damage and lung inflammation induced by physical exercise are described. Changes in lung function induced by exercise involve cooling of the airways, fluid evaporation of the epithelial surface, increased contact with polluting substances, and activation of the local and systemic inflammatory response. The present work includes evidence obtained from the different types of exercise in terms of duration and intensity, the effect of both acute performance and chronic performance, and the influence of special conditions such as cold weather, high altitude, and polluted environments. Levels of prooxidants, antioxidants, oxidative damage to biomolecules, and cellularity, as well as levels of soluble mediators of the inflammatory response and its effects on tissues, are described in samples of lung origin. These samples include tissue homogenates, induced sputum, bronchoalveolar lavage fluid, biopsies, and exhaled breath condensate obtained in experimental protocols conducted on animal and human models. Finally, the need to simultaneously explore the oxidative/inflammatory parameters to establish the interrelation between them is highlighted.
\end{abstract}

\section{Introduction}

When doing physical exercise, the usual levels of organic performance are exceeded. However, we are designed to execute the exercise, depending on its variety, duration, intensity, and the environmental conditions under which it is done. The physiological and pathological processes will be activated, which can lead to the generation of an oxidative imbalance and the establishment of an inflammatory process $[1,2]$. The oxidative damage happens as an additional cost of using oxygen to obtain energy and can occur when there is an increase in the formation of prooxidants and/or when the antioxidant defense decreases, causing an alteration of tissue product functionality of the structural damage to all the cellular components that contain lipids, carbohydrates, proteins, and nucleic acids [3]. Another response mechanism to physical stress is inflammation, which is triggered as a reaction to the mechanical damage of structural components (connective tissue; muscle, tendon, and bone) and nonstructural components (erythrocytes, endothelium, and epithelia) of the body [4-8]. As a result, stress hormones are released, such as cortisol and catecholamines, which activates the immune system, causing a particular response profile based on the release of soluble mediators (cytokines) and arachidonic acid derivatives (prostaglandins and leukotrienes). The latter and the stress hormones will cause changes in the number and activation of leukocytes subpopulations to the point that intense exercise of long duration can induce immune suppression (increasing the susceptibility to infection) [9], in contrast to the exercise of moderate intensity, which boosts the immune response. Both the alteration of the redox system and the inflammatory reaction have multiple 
points of interaction that have been previously evidenced [10-12]. The study of inflammatory/oxidative damage at a pulmonary level has been a topic poorly addressed [1315], particularly in healthy humans and even more so in athletes. Most of the information in this subject arises from pathophysiology of pulmonary diseases, such as asthma, cystic fibrosis, and chronic obstructive pulmonary disease [16-27]. The lung has the crucial role of gas exchange and experiences great modifications of its activity during the exercise. This mobilizes larger volumes of air and modifies the breathing pattern from nasal to oral, increasing contact with a greater amount of pollutants that may be present in the environment. Also, the lung receives a greater amount of blood flow to increase the exchange in places that are well ventilated, which causes changes in the functioning of the vascular parenchyma $[28,29]$. However, the anatomofunctional characteristics of the lungs make it very difficult to obtain information of the redox/inflammatory state in the different sectors of this organ. This work brings together the scientific papers that have addressed the phenomenon of altered pulmonary redox/inflammation environment induced by acute or chronic exercise, in a hypoxic environment, cold or contaminated, in both animal and human models, by focusing on the protocols and mechanisms that explain the phenomenon, as well as their potential implication on those who exercise.

\section{Effects of Exercise on the Respiratory System and Its Relationship with the Generation of Oxidative/Inflammation Damage}

When exercising, the mobilized air flow or pulmonary ventilation increases. This is explained by the increase of the respiratory rate, the tidal volume, and the appearance of bronchodilation. In addition to this, the pulmonary vascular bed will vasodilate to receive a greater blood flow. These changes, taken together, aim to increase gas exchange. Large air flows entering the lung during exercise will cause a modification of the breathing pattern towards one predominantly oral, favoring the evaporation of the fluid covering the pulmonary epithelium and the decrease of temperature of the airways. As a result, the pulmonary passages will cool down and the osmolarity of the epithelium will increase [30]. It should be noted that the cooling of the pulmonary passages as a result of the hyperventilation has been observed at comfortable environment temperature $\left(+20^{\circ} \mathrm{C}\right)$ [31]. In this way, McFadden Jr. and Pichurko [31] showed a decrease of the tracheal temperature of $34^{\circ} \mathrm{C}$ at pulmonary ventilation of $15 \mathrm{~L} / \mathrm{min}$ and of $31^{\circ} \mathrm{C}$ at $100 \mathrm{~L} / \mathrm{min}$. The cooling of the airway by hyperventilation produced by exercise is homologous to breathing cold air at rest. The latter is probably in the absence of air pollutants, the main irritative/proinflammatory factor of this region of our body. In cold environments, there is a greater amount of reports of respiratory symptoms [32] and chronic changes of epithelium similar to those of patients with chronically inflamed airways (e.g., asthmatics). Some authors observed, in humans, that the product of intense exercise appears to have similar symptoms to those observed in infection of upper airways [33-35]. However, with moderate training these symptoms decreased [36, 37]. It is probable that intense exercise of long duration, such as a marathon, will increase the susceptibility to infection of the airway by depression of the immune function, contrary to the effect caused by exercise of moderate intensity. Another factor involved in the oxidative/proinflammatory process of the airway is the greater contact with toxic particles and microorganisms present in the environment due to hyperventilation by exercise [38-40]. For example, the damaging effect on lung tissue of environmental substances such as chlorine, ozone, nitrogen oxides, particulate matter, and pollen is recognized $[14,41-43]$. The entry of these substances by the pulmonary route can potentially generate systemic inflammation $[44,45]$ and this will affect the lungs. Finally, another factor of the recognized destabilizing effect of the oxidative balance and in favor of pulmonary inflammation is hypoxia [46, 47]. The general framework for the development of functional changes of the lung by exercise, the activation of the redox imbalance, and the inflammatory system are described in Figure 1.

\section{Changes in Pulmonary Redox State and Exercise-Induced Inflammation}

As mentioned previously, physical exercise induces changes in the redox/inflammatory state of the organism, at both systemic level and the different organs. In this regard, lung is one of the less studied organs in this context. In the following paragraphs, the most relevant results regarding pulmonary oxidative damage and inflammation caused by exercise are summarized. In this review, the work carried out in healthy subjects was privileged. Regarding the special conditions, hypoxia, water contaminants (chlorine), and cold have been included, leaving aside air pollutants, because there are several reviews regarding this subject $[48,49]$. The details of the studies included in terms of goals, characteristics of the sample, the protocol used, and the results related to the pulmonary oxidative/inflammation damage by exercise are summarized in Tables 1 and 2 for human and animals, respectively.

\section{Pulmonary Redox Balance and Acute Exercise}

A direct relationship has also been reported during exercise, between the acute exercise intensity and the volume of exhaled nitric oxide (VNO), namely, volume minute (VE) multiplied by exhaled nitric oxide (eNO), for sedentary healthy $[50,60,68,69,71,82,85-87,90]$ and trained subjects $[75,89]$. During exercise, eNO have been reported to be decreased when increasing $\mathrm{VO}_{2}[59,75]$ and $\mathrm{VE}$ [75] in sedentary and active subjects $[51,60,68,69,75,82,85,86,92]$. In athletes, unlike Maroun et al. [75], Kippelen et al. [68] showed changes in eNO during exercise. In animal model, while exercising healthy horses, Mills et al. [112] observed a linear increase of the VNO as the oxygen consumption increased. After exercise, nitric oxide concentrations have 


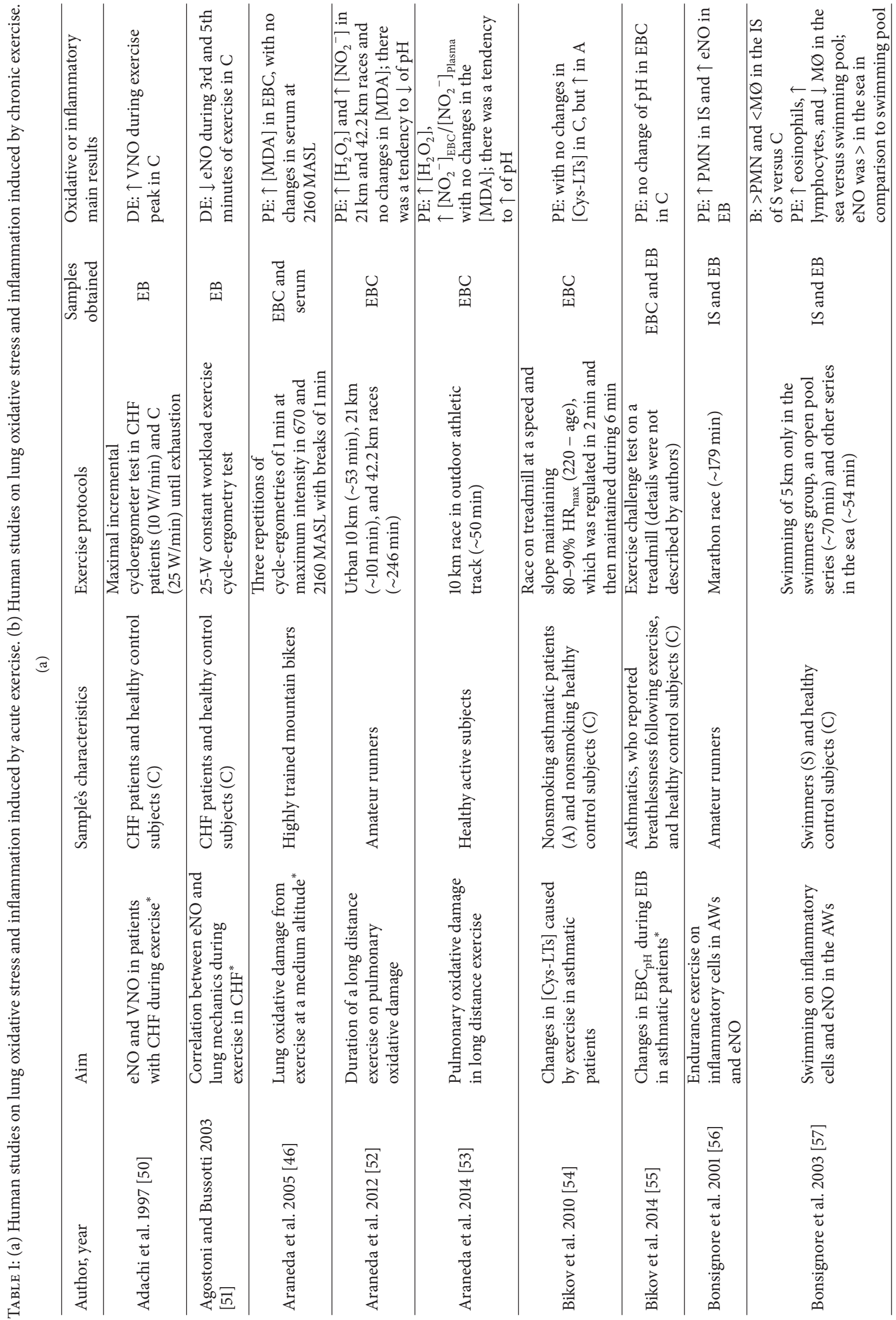




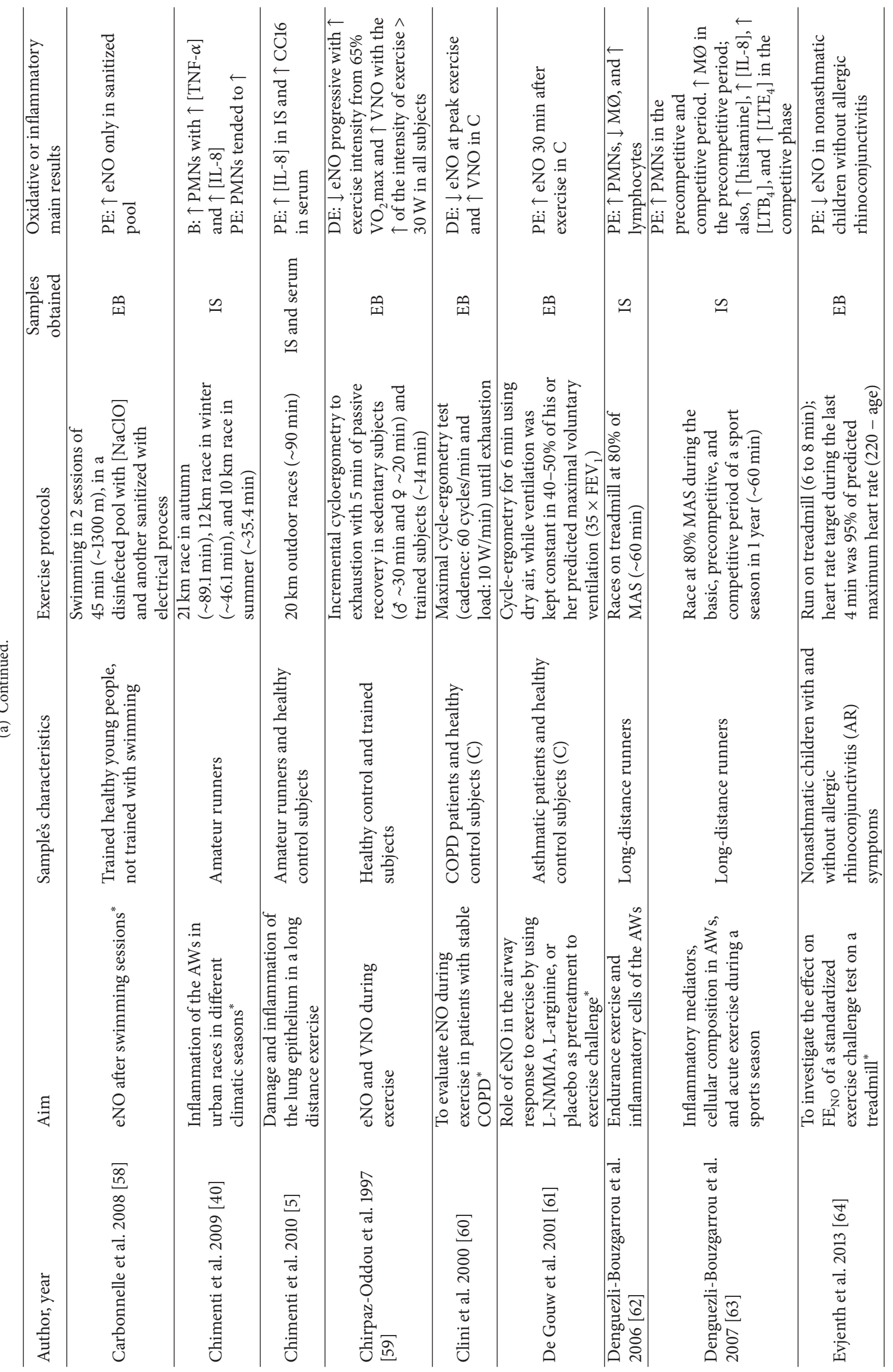




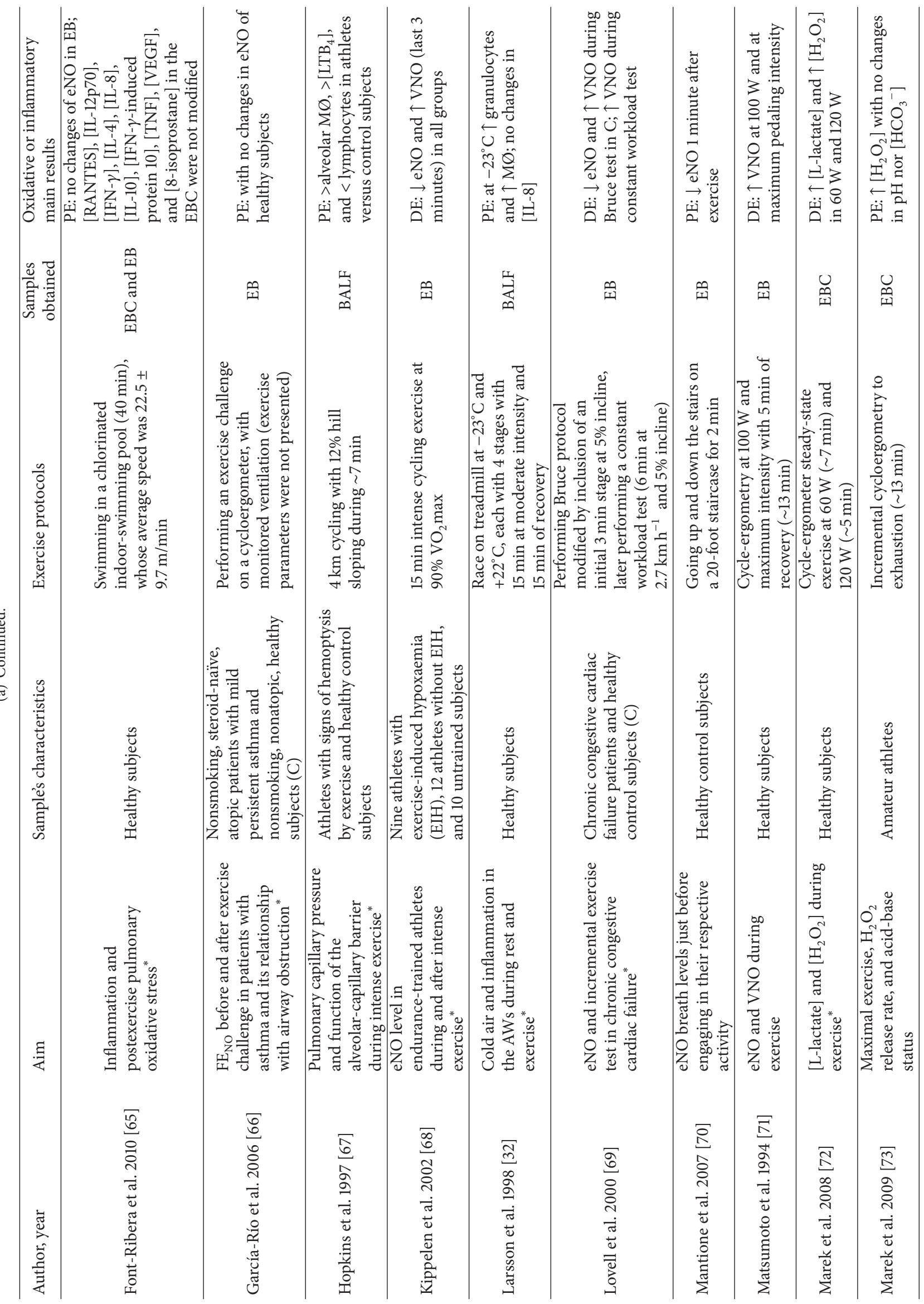




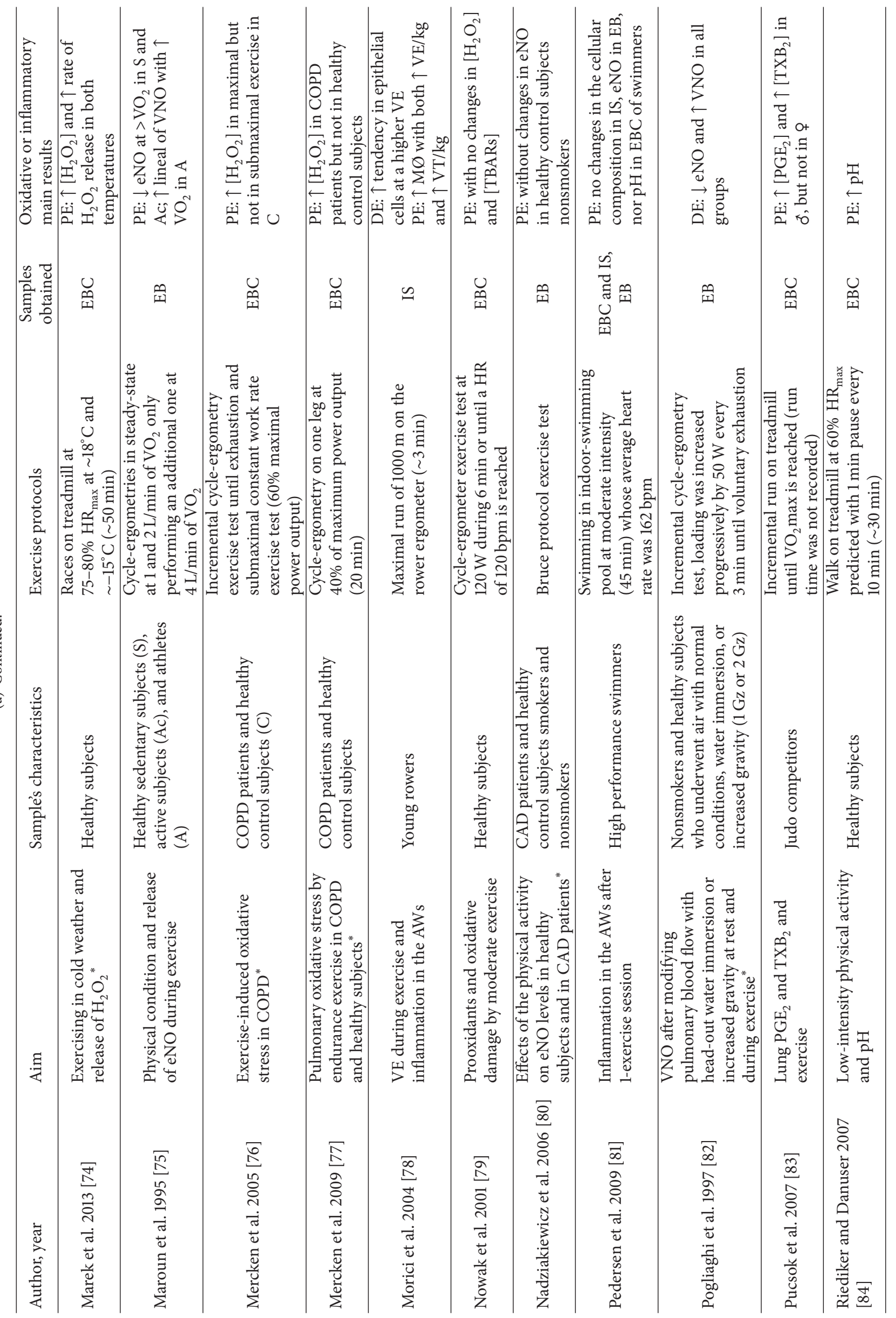









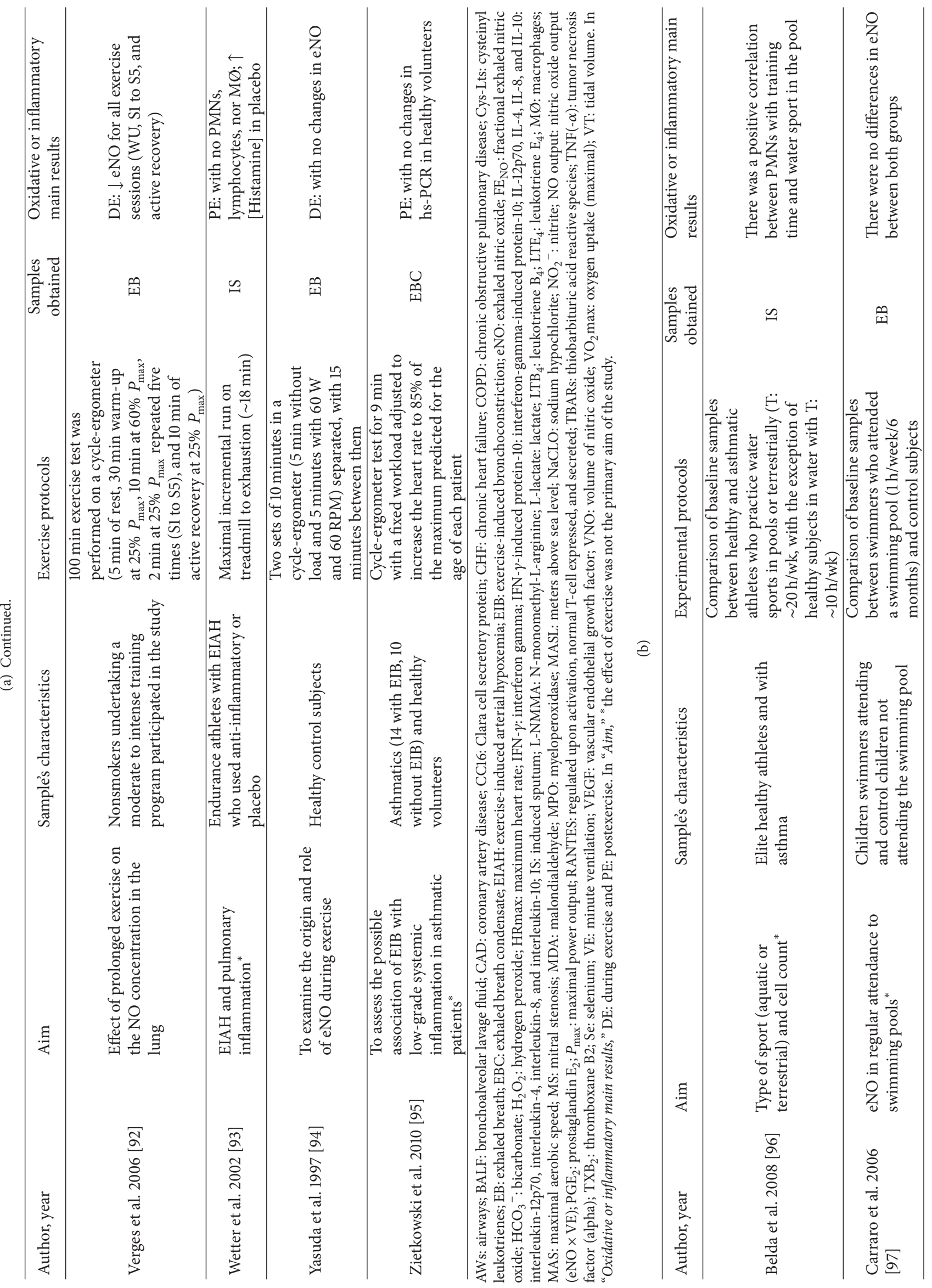




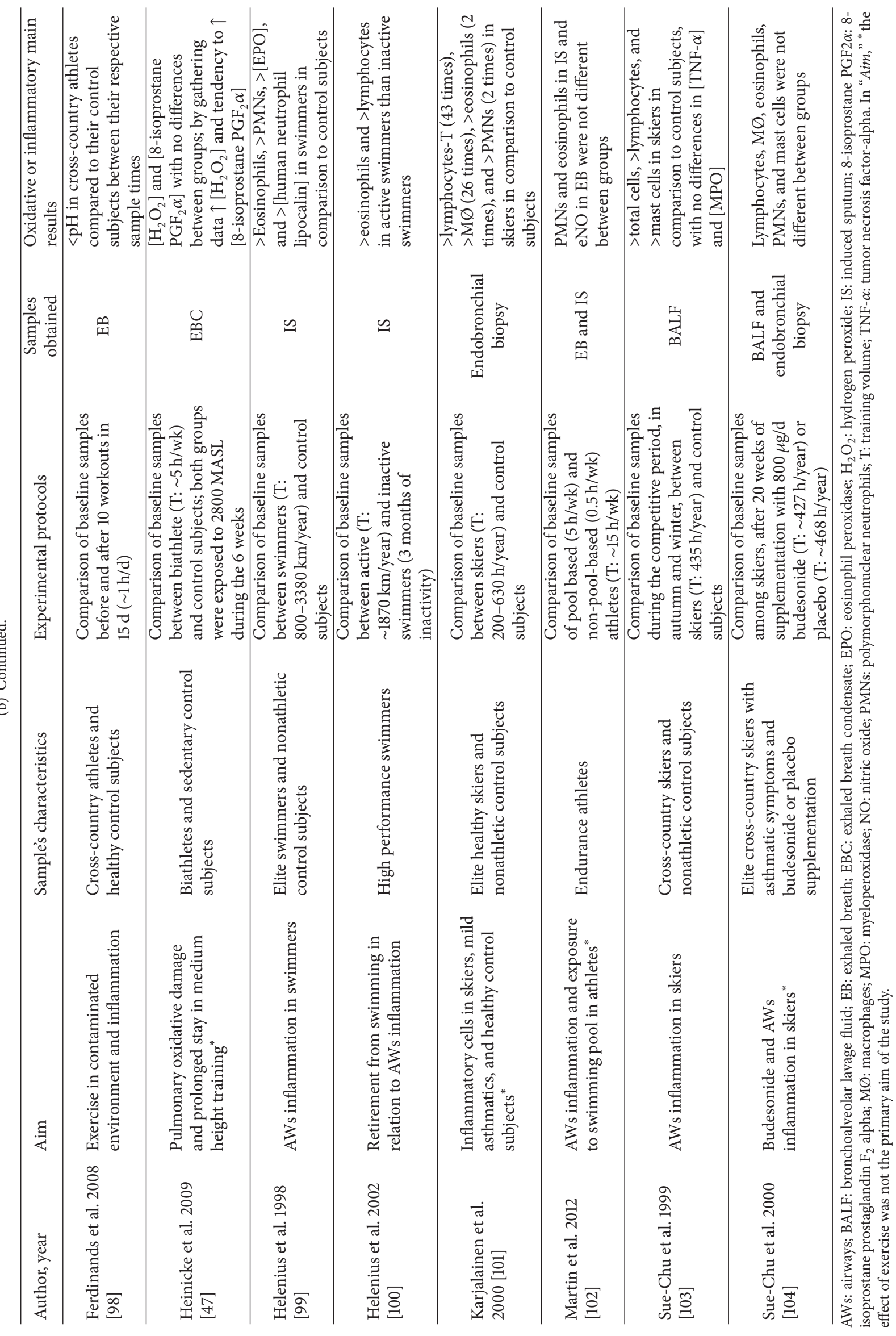




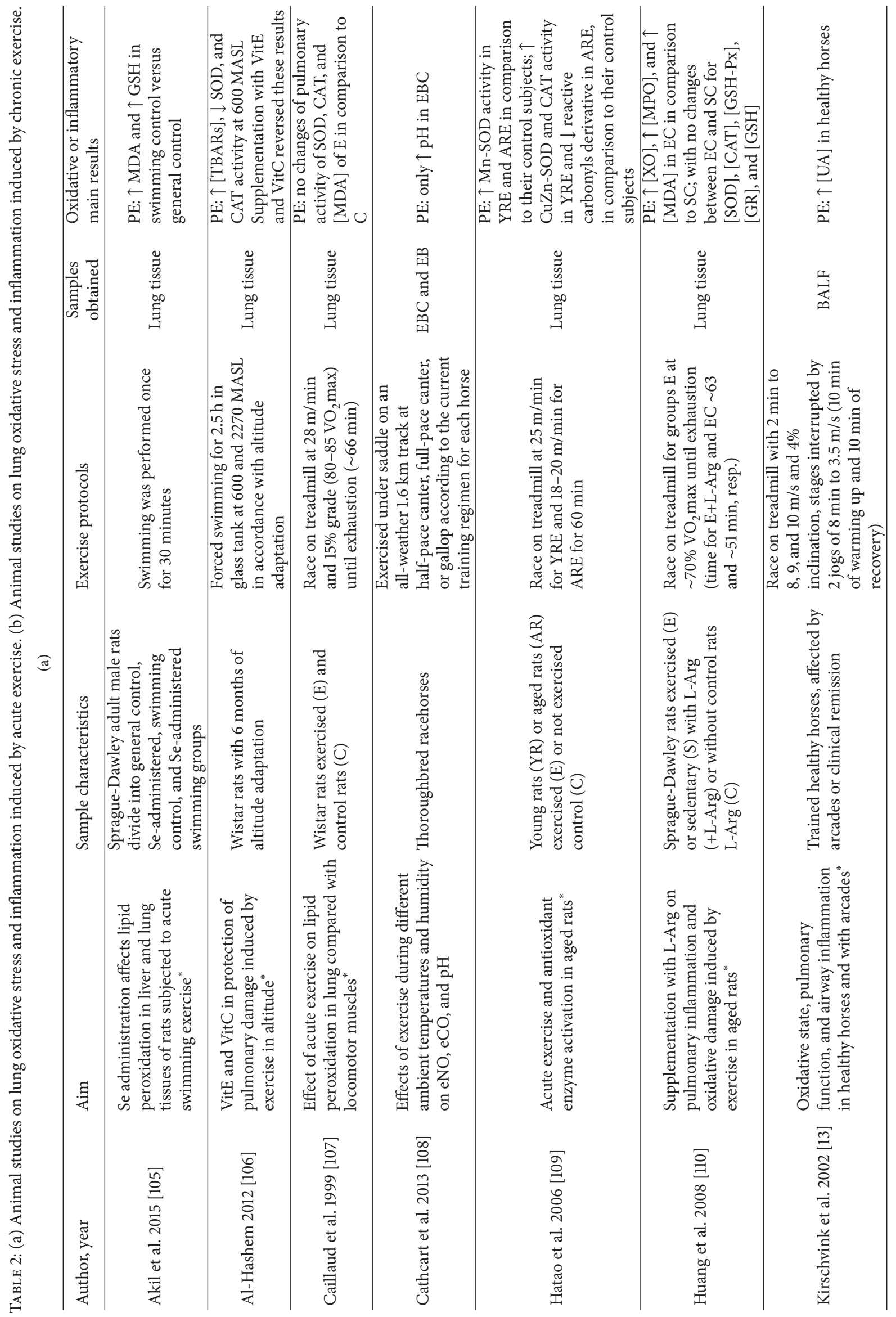




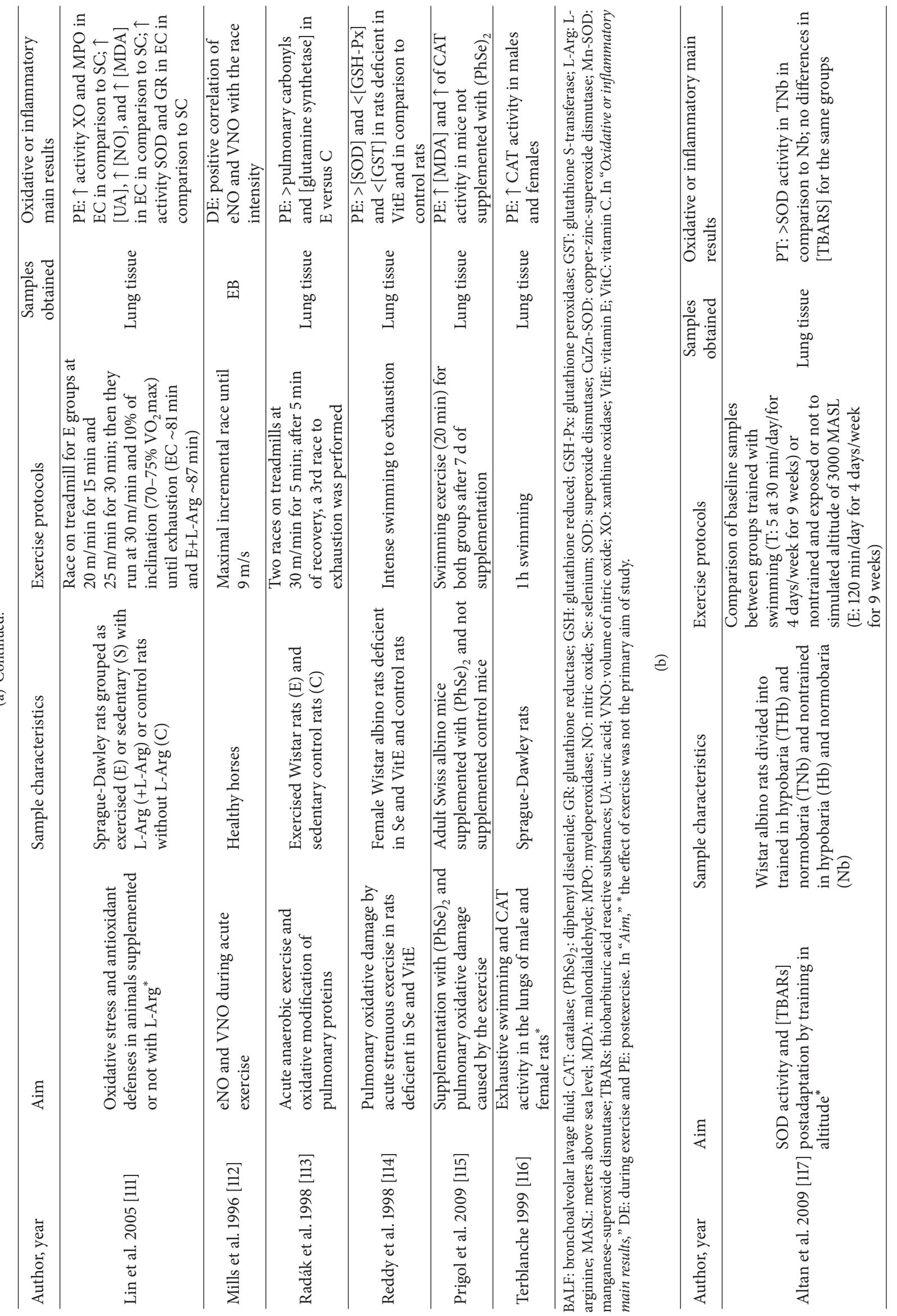




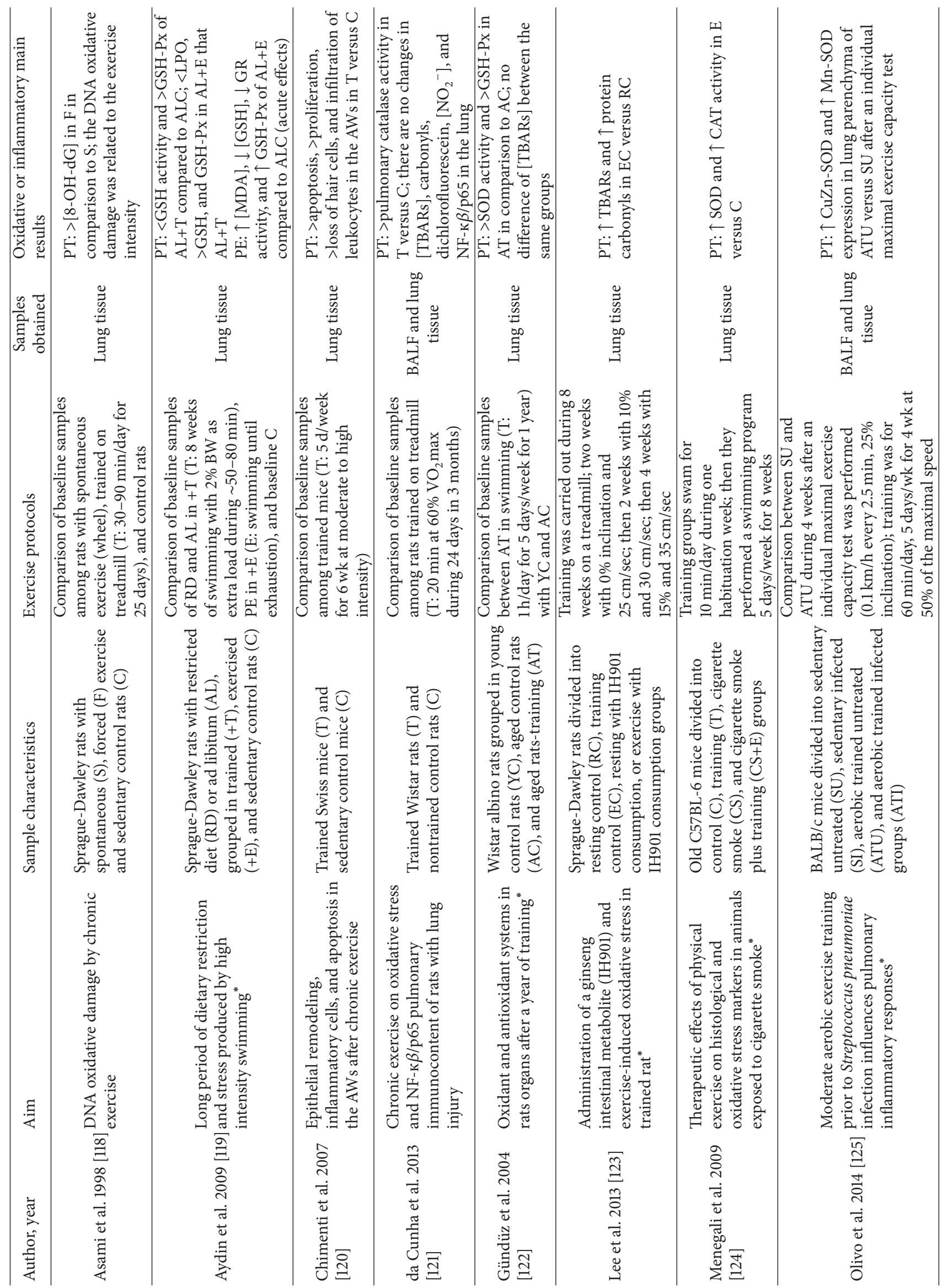




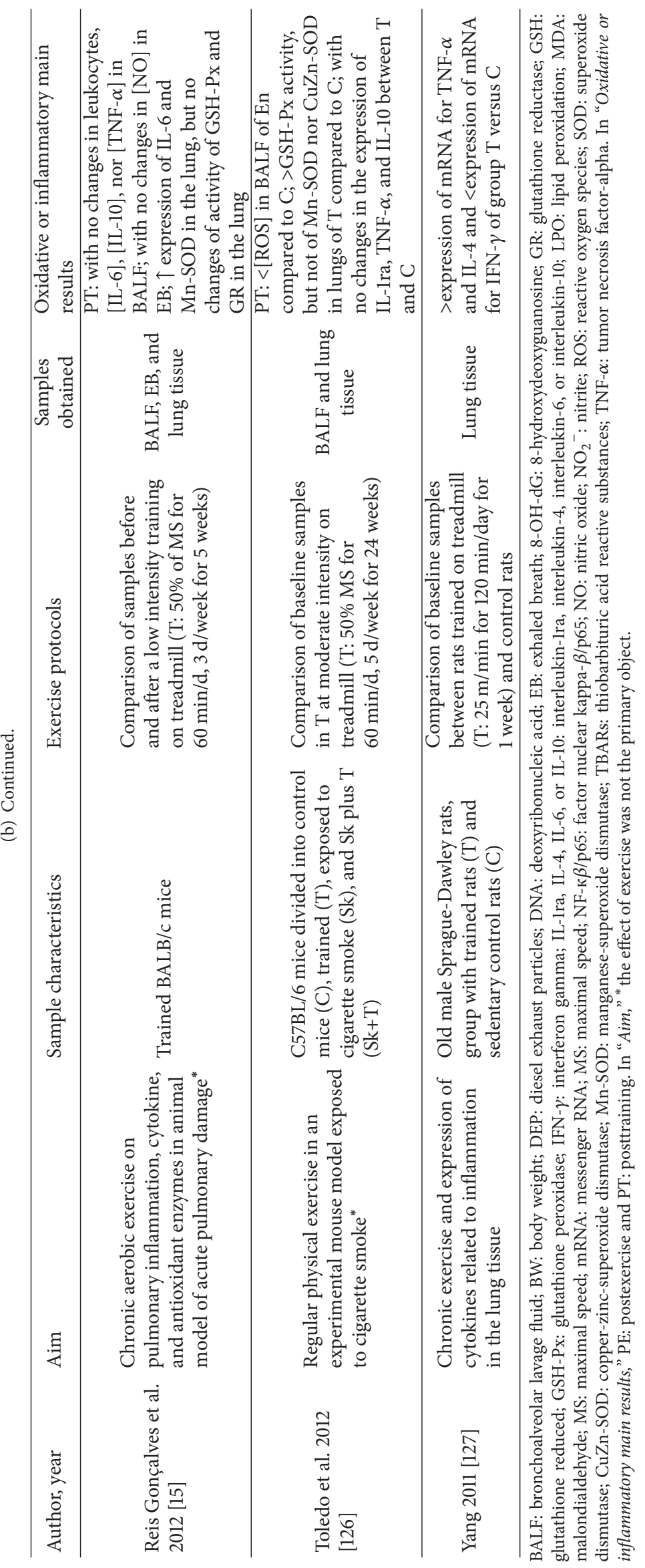




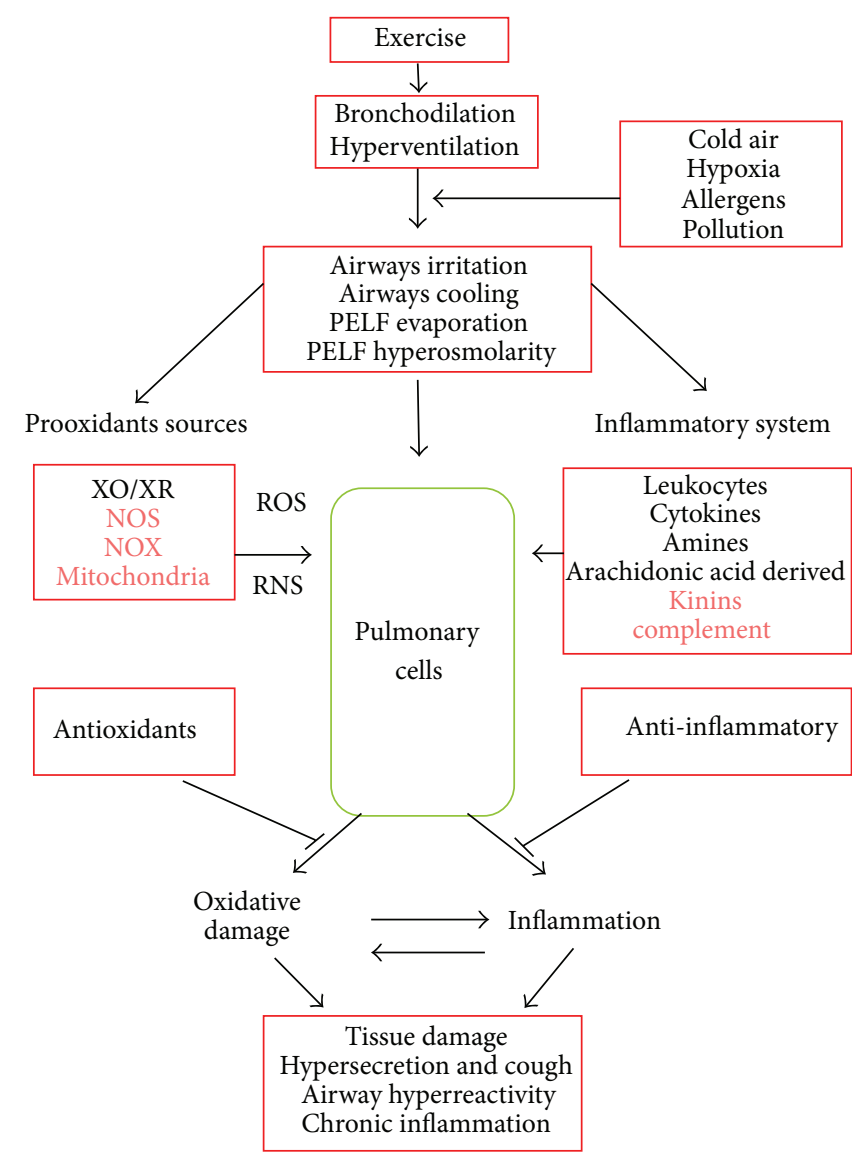

FIGURE 1: Proposed mechanisms related to the process of oxidative damage and pulmonary inflammation induced by exercise. Once the exercise starts the pulmonary ventilation increases and favors bronchodilation. This cools the airways, and also the part of PELF evaporates with subsequent increase of osmolarity and irritation appears. This activates the generating sources of free radicals and the inflammatory system. As a result of the foregoing, oxidative damage and a concomitant inflammatory process are potentially generated at pulmonary cell level; this may involve tissue damage, the increase of cough and the increased secretion of mucus, and the appearance of bronchoreactive phenomena and in the case that this stimulus is repeated (chronic exercise) to establish a process of chronic inflammation and remodeling of pulmonary tissue, particularly in the airways. This process is exacerbated when the exercise is performed in the presence of environmental conditions such as cold and hypoxia, in environments where pollen is abundant or in presence of contaminants (water/air). In red color the prooxidants sources and the parts of the inflammatory system that have not been studied are both appreciated. XO/XR $=$ xanthine-oxidase/dehydrogenase; NOS = nitric oxide synthase; NOX = NADPH oxidase; PELF = pulmonary epithelial lining fluid.

shown controversial results. In swimmers, Bonsignore et al. [57] reported a decreased eNO after $5 \mathrm{~km}(\sim 179 \mathrm{~min})$ in slightly chlorinated pool; when performing the same test at the sea no changes were observed in this pair but the same distance was maintained at the sea. In other studies, also a decreased eNO after exercise has been observed in healthy subjects $[64,70,88,91]$. However, in youngsters not trained in swimming, Carbonnelle et al. [58] found increases of eNO after swimming 2 sessions of $\sim 1300 \mathrm{~m}$ in $45 \mathrm{~min}$ in a pool sanitized with electrical process (nonchlorinated water). Also, De Gouw et al. [61] found an increased eNO in healthy subjects after cycling for 6 min using dry air, while ventilation was kept constant in $40-50 \%$ of his or her predicted maximal voluntary ventilation $\left(35 \times \mathrm{FEV}_{1}\right)$. Other studies showed no changes in the eNO after exercise; Font-Ribera et al. [65] found no differences in eNO concentrations in pool swimmers; the same occurred with eNO in swimmers after an exercise of $45 \mathrm{~min}$ [81] and in healthy subjects after either cycloergometer $[66,94]$ or treadmill incremental exercise test [80].

Through the exhaled breath condensate (EBC) analysis, to observe the oxidative effects of the moderate acute exercise, Nowak et al. [79] subjected a group of healthy subjects to a submaximal exercise on cycloergometer during $\sim 6 \mathrm{~min}$; they found no changes in $\mathrm{H}_{2} \mathrm{O}_{2}$ and thiobarbituric acid reactive substances (TBARs). Araneda et al. [46] found no changes of $\mathrm{H}_{2} \mathrm{O}_{2}$ in EBC after three maximal cycle ergometries of $1 \mathrm{~min}$ in elite cyclists carried out at 670 and 2160 masl, but malondialdehyde (MDA) was higher at 2160 meters. Marek et al. [72], in two submaximal cycle ergometries to $60 \mathrm{~W}$ $(\sim 7 \mathrm{~min})$ and $120 \mathrm{~W}(\sim 5 \mathrm{~min})$, and later in maximal exercise ( $\sim 13 \mathrm{~min}$ ), found no differences in $\mathrm{H}_{2} \mathrm{O}_{2}$ concentration in EBC [73]; however, in both studies, increases were found in the flow of formed $\mathrm{H}_{2} \mathrm{O}_{2}$ after exercise. On the same prooxidant, Mercken et al. [76] found an increase after maximal cycle ergometry in healthy subjects, with increments of $10 \mathrm{w} / \mathrm{min}$, but they did not find any differences in subjects with chronic obstructive pulmonary disease after exercise. However, in another study they found no differences in $\mathrm{H}_{2} \mathrm{O}_{2}$ when healthy subjects performed a cycle ergometry with one leg $\left(40 \% P_{\max }\right)$ during $20 \mathrm{~min}$ [77]. Marek et al. [74] found that, after $50 \mathrm{~min}$ of high intensity running developed at $\sim 18^{\circ} \mathrm{C}$ and $\sim-15^{\circ} \mathrm{C}$ of environmental temperature, the concentration and production rates of $\mathrm{H}_{2} \mathrm{O}_{2}$ in $\mathrm{EBC}$ were higher when the exercise was carried out in a cold environment. Recently an increase in $\mathrm{H}_{2} \mathrm{O}_{2}$ and nitrite concentrations and correlations between both metabolites in the EBC of 21 and $42.2 \mathrm{~km}$ race participants were found. Also in this study, while nitrite increased in $\mathrm{EBC}$, plasmatic nitrite showed no modifications and no correlations between these variables, which suggests a probable localized origin of this process [53].

Until now, only two studies have determined one of the potential sources of prooxidants; thus, it has been described as an increment of xanthine oxidase activity in the pulmonary homogenate of rats that performed strenuous exercise ( $15 \mathrm{~min})$ on a treadmill $(20 \mathrm{~m} / \mathrm{min})$, besides MDA and NO [111]. Likewise, Huang et al. [110] observed an increase of the activity of xanthine oxidase and lung MDA in older rats after running on a treadmill until fatigue, during $\sim 63 \mathrm{~min}$ at $70 \% \mathrm{VO}_{2}$ max. Prigol et al. [115] and Akil et al. [105] found increases in TBARs in rats that swam for $20 \mathrm{~min}$ and $30 \mathrm{~min}$, respectively, while Reddy et al. [114] found increases in MDA in rats with a vitamin $\mathrm{E}$ deficient diet that swam until fatigued. Also in rats, increases of TBARs after swimming during $\sim 2.5 \mathrm{~h}$ until fatigue were found [106]. The same result was found in pulmonary homogenates of untrained rats which 
swam until exhaustion [119]. A strenuous exercise protocol of $\sim 66 \min \left(80-85 \% \mathrm{VO}_{2} \mathrm{max}\right)$ showed no changes in TBARs in rats [107].

In healthy horses, no differences were observed in isoprostane 8-epi-PGF2 $\alpha$ of supernatant of bronchoalveolar lavage fluid (BALF) after 50 min of running [13]. An increment of carbonyls in the lungs of rats was observed by Radák et al. [113] after an exercise till exhaustion on the treadmill. However, after an hour of a moderate intensity run in young and old rats, no changes were observed in the lung carbonyls [109].

With regard to the pulmonary antioxidant enzymes, after an hour of acute moderate exercise protocols on treadmills, young rats' lungs showed an increase in the activity of enzymes superoxide dismutase (SOD) of the type CuZnSOD, Mn-SOD, of the catalase (CAT), without changes in the glutathione peroxidase (GSH-Px). The mRNA expression for these enzymes did not show differences [109]. Lin et al. [111] found an increase in SOD and glutathione reductase (GR) activity with no changes in CAT and GSH-Px activity in rats that ran at $30 \mathrm{~m} / \mathrm{min}$ and $10 \%$ slope until fatigued. Finally, acute and prolonged exercise (more than an hour) at $80-85 \% \mathrm{VO}_{2} \max$ showed no changes in the activity of GSH-Px and SOD [107]. In acute exercise protocols, using swimming, Reddy et al. [114] found an increase in SOD and glutathione transferase (GST), while mild decreases in GSH-Px activity were observed in rats that swam until fatigued. Prigol et al. [115] found increase in CAT activity in rats that swam for $20 \mathrm{~min}$. In rats that exercise for an hour, Terblanche [116] found increased CAT activity without differences between males and females. In rats 18 months old, Huang et al. [110] described an increase of SOD activity and the maintenance of levels of CAT, GSH-Px, and GR after $51 \mathrm{~min}$ on treadmill at $70 \%$ of $\mathrm{VO}_{2}$ max. Strenuous exercise increased the activity of GSH-Px, with no changes in GR [119]. In a report of Al-Hashem et al. [106], rats that exercised until fatigue decreased the activity of SOD and CAT.

Acute exercise has also altered the levels of nonenzymatic antioxidants; an increase of uric acid has been described, with no changes in total glutathione, in GSH, and in GSSG in BALF, after $50 \mathrm{~min}$ of incremental exercise in healthy horses [13]. In a study of rats that ran during $\sim 81 \mathrm{~min}$ at $70-$ $75 \% \mathrm{VO}_{2}$ max until fatigue, no variations were found in the homogenized lung GSH [111]. In rats that swam until fatigue $(\sim 2.5 \mathrm{~h})$, no differences were found at $600 \mathrm{~m}$ of altitude, but there was a decrease of GSH levels at 2270 meters [106]; in this same report, it was found that supplementation with nonenzymatic antioxidants such as VitC $(20 \mathrm{mg} / \mathrm{kg})$ and VitE $(20 \mathrm{mg} / \mathrm{kg})$, a single dose one hour before starting the exercise, decreases pulmonary lipid peroxidation and SOD and CAT activities increases, in both altitudes. Additionally, supplementation shows higher levels of GSH compared to animals not treated in altitude [106].

Thus, the increase in lung prooxidants and its consequences (lipid peroxidation) due to acute exercise appear to be related to the high intensity and duration of the effort, in terms of either minute ventilation or oxygen consumption, and are enhanced by a hostile environment (hypoxia, pollution, cold, etc.). However, a mainly enzymatic antioxidant adaptive response is still controversial. In contrast, the use of vitamin reducers (C and $\mathrm{E}$ ) allows the antioxidant capacity to be increased and oxidative damage to be controlled (see Tables 1(a) and 1(b)).

\section{Pulmonary Redox Balance and Chronic Exercise}

In a first study of pulmonary prooxidants and chronic exercise, Carraro et al. [97] found no differences in eNO of child swimmers (trained $1 \mathrm{~h}$ /week during 6 months). Martin et al. [102] observed no differences in eNO of athletes based in pool and not based in pool exposed to pool environment during 5 and $0.5 \mathrm{~h} /$ week, respectively. For oxidative damage, Heinicke et al. [47] found a tendency towards increase of 8isoprostanes in the EBC of biathletes who trained at 2800 meters during 6 weeks ( $4-6 \mathrm{~h} / \mathrm{d}$ with $1 \mathrm{~d} /$ weeks of rest), which included extensive cross-country skiing, strength training, and shooting technique training.

In a model of physical training of rats, which jogged in 3 months a total of 24 sessions of $20 \mathrm{~min} / \mathrm{d}$ at $60 \% \mathrm{VO}_{2} \max$, no differences were found in pulmonary carbonyls, nitrite, or TBARs [121]. After 24 weeks of training at $50 \% \mathrm{~V}_{\max }$ for $60 \mathrm{~min} / \mathrm{d}$ for $5 \mathrm{~d} /$ week, ROS decreased in BALF and no changes of increase were found in pulmonary 8-isoprostanes in trained mice [126]. Using the same load and frequency as before, the levels of eNO and MDA were not altered in lung homogenates of rats trained during 5 weeks [15]. However, during the 8 weeks of training in rats that swam with a $2 \%$ of additional body weight during $~ 50-80 \mathrm{~min}$, an increment of pulmonary carbonyls and MDA was observed [119]. Gündüz et al. [122] found increases of TBARs in older rats (21 months) versus young rats (9 months), without any variations between old rats which were either trained or untrained in swimming during 12 months $1 \mathrm{~h} / \mathrm{d}$ for $5 \mathrm{~d} /$ week. Altan et al. [117] found increases in MDA in rats trained at 3000 meters of altitude $(120 \mathrm{~min} / \mathrm{d}$ for $4 \mathrm{~d} /$ week during 9 weeks) compared to sedentary control rats and the ones not trained maintained at sea or height level. In Sprague-Dawley rat that was trained during 8 weeks on a treadmill, an increase in pulmonary TBARs and protein carbonyls was observed [123]. Regarding oxidative stress on nucleic acids, Asami et al. [118] found increases in 8-hydroxydeoxyguanosine in rats after a forced race on treadmill for five weeks in daily sessions with a gradual increase in the time of $30-$ $90 \mathrm{~min}$.

The chronic exercising has also had as a subject of study the potential changes of the expression/activity of the enzymes and nonenzymes pulmonary antioxidant. Likewise, Reis Gonçalves et al. [15] found an increase in the lung MnSOD expression of mice subjected to five weeks of training at moderate intensity $(60 \mathrm{~min} / \mathrm{d}$ in $3 \mathrm{~d} / \mathrm{wk})$; however, no changes were observed in the GSH-Px, GR, GST, and CAT activities. In another study, Olivo et al. [125] observed an increased expression in pulmonary CuZn-SOD and Mn-SOD postmaximal exercise test of trained mice during 4 weeks at $50 \%$ of the maximal speed on treadmill. Altan et al. [117] 
found increases of SOD activity after nine weeks of progressive training in a normobaric environment ( 5 to $30 \mathrm{~min} / \mathrm{d}$ for $4 \mathrm{~d} /$ week), with no differences with a trained group at 3000 meters of altitude. da Cunha et al. [121] observed a higher pulmonary CAT activity in the ones trained on a treadmill during 12 weeks at $60 \% \mathrm{VO}_{2} \max (20 \mathrm{~min} / \mathrm{d})$, compared to control rats. In another study, Menegali et al. [124] found an increase of the CAT and SOD activity in lung of trained rat in swimming during 8 weeks. In mice trained on a treadmill for 24 weeks at $50 \% \mathrm{~V}_{\max }(60 \mathrm{~min} / \mathrm{d}$ and $5 \mathrm{~d} /$ week $)$ increases of GSH-Px were observed without changes of expression of CuZn-SOD, Mn-SOD, and Ec-SOD, studied in sections of pulmonary tissue [126]. In another study, older animals of 21 months that were trained for a year ( $1 \mathrm{~h} / \mathrm{d}$ and $5 \mathrm{~d} /$ week) had a greater amount of SOD in comparison to control rats of their same age and to young rats. No differences were found in CAT activities, while GSH-Px had a greater activity than a group of their same age [122]. Finally, Aydin et al. [119] observed a decrease in the concentrations of GSH and an increase of GSH-Px activity in pulmonary homogenates of rats, after eight weeks of swimming with overload and progressive weekly time increment (50-80 min).

This reflects the fact that oxidative stress induced by chronic pulmonary exercise in animals is closely associated with high-intensity protocols, but not with those of moderate intensity (see Table 1(b)). However, when moderate chronic exercise was executed while at high altitude, both human and animals presented pulmonary oxidative damage (see Tables (b) and 2(b)). In contrast, antioxidant adaptation seems to be more closely related to the animal training time, with an increase in the activity of SOD and CAT in the medium term and the expression of SOD in the short term (see Table 2(b)).

\section{Acute Exercise-Induced Lung Inflammation}

In horses, Kirschvink et al. [13] found no cellular count variation in BALF after 50 minutes of exercise. In runners' sputum of $10 \mathrm{~km}(\sim 35.4 \mathrm{~min}), 12 \mathrm{~km}(\sim 46.1 \mathrm{~min})$, and $21 \mathrm{~km}$ $(\sim 89.1 \mathrm{~min})$ a trend of increasing polymorphonuclear neutrophils (PMNs) in samples of induced sputum was found [40]. In the same direction, Bonsignore et al. [56] reported a higher percentage of PMNs in induced sputum, compared to values previous to exercise and an increase in these cells after the marathon ( $179 \mathrm{~min})$. Also in induced sputum of runners, Denguezli-Bouzgarrou et al. observed in 2006 [62] and 2007 [63] an increase of PMNs after 60 minutes of moderate racing. In the latter study, higher concentrations of histamine, interleukin-8 (IL-8), $\mathrm{LTB}_{4}$, and LTE4 were also detected, subsequent to acute exercise during the precompetitive phase versus the competitive phase [63]. Chimenti et al. [5], in a 20kilometer race ( $\sim 90 \mathrm{~min})$, reported an increase in IL-8 in the supernatant. Races in smaller time frames ( $18 \mathrm{~min})$ showed no changes in the amount of PMNs in induced sputum [93]. In rowers, after a short test of high intensity $(1000 \mathrm{~m}$ in $\sim 3 \mathrm{~min}$ ), there was a trend towards an increase of epithelial cells and a positive association between the pulmonary ventilation/body weight $(\mathrm{L} / \mathrm{kg})$ and macrophages in induced sputum [78]. In swimmers, increases in lymphocytes and eosinophils and a decrease in macrophages were observed in induced sputum, after a $5 \mathrm{~km}$ race in the ocean (hypertonic environment) in relation to the same test performed in an open pool with low concentration of chlorine. However, there is no evidence of the increase in inflammatory cell activation [57]. In a chlorinated pool, in high performance swimmers, no changes were observed in the cellular composition of the induced sputum and the $\mathrm{pH}$ in $\mathrm{EBC}$ after $45 \mathrm{~min}$ at moderate intensity [81]. Larsson et al. [32] found an increase of granulocytes and macrophages in subjects that performed one hour of exercise, on a treadmill, at $-23^{\circ} \mathrm{C}$, without IL- 8 changes in BALF samples. Derivatives of arachidonic acid have been studied in three works; thus, in a maximum acute exercise of approximately $12 \mathrm{~min}$, increases in $\mathrm{E}_{2}$ prostaglandin and $\mathrm{B}_{2}$ thromboxane in $\mathrm{EBC}$ after exercise were found in men [83]. The leukotrienes in EBC were studied by Bikov et al. [54]; thus, after an eight-minute test on a treadmill no differences in the concentration of cysteinyl leukotrienes were found in normal people. In a test of $4 \mathrm{~km}$ of cycling with a $12 \%$ hill sloping during $\sim 7 \mathrm{~min}$, an increase of leukotriene B4 in BALF of athletes was found in comparison to the control subjects [67]. Also in EBC, Zietkowski et al. [95] found no changes in high sensitive $\mathrm{C}$-reactive protein after 9 minutes of cycle-ergometry at $85 \%$ of $\mathrm{HR}_{\max }$ in healthy subjects.

The $\mathrm{pH}$ in $\mathrm{EBC}\left(\mathrm{EBC}_{\mathrm{pH}}\right)$ is a potential marker of pulmonary inflammation that has been used in pathologies that have this condition. In acute exercise, the results have been variable; thus, Marek et al. [73] did not find differences after an exercise until fatigue $(\sim 13 \mathrm{~min})$ in $\mathrm{EBC}_{\mathrm{pH}}$ of amateur athletes. Bikov et al. [55] did not observe changes in the $\mathrm{EBC}_{\mathrm{pH}}$ of healthy subjects after exercise, while there are other reports that show increases in $\mathrm{pH}$ after outdoor exercise [128] and after low-intensity $\left(60 \% \mathrm{HR}_{\max }\right)$ exercise ( 30 min) in nonathlete healthy subjects [84]. In races up to $10 \mathrm{~km}$, no changes have been reported up to $80 \mathrm{~min}$ after the race, in both amateur runners [52] and physically active runners [53]. However, there are inverse correlations between changes in prooxidants and changes of $\mathrm{EBC}_{\mathrm{pH}}$ [53]. In distances that exceed 21 and $42 \mathrm{~km}, \sim 101 \mathrm{~min}$ and $\sim 246 \mathrm{~min}$, respectively, an acute decreasing trend of $\mathrm{EBC}_{\mathrm{pH}}$ was observed [52]. However, in an animal study conducted in horses, the group of Cathcart et al. [108] found an increase in $\mathrm{EBC}_{\mathrm{pH}}$ after running $1.6 \mathrm{~km}$.

In summary, the majority of published papers demonstrate the infiltration of inflammatory cells (macrophages or granulocytes) after acute exercise in humans. A factor that probably influences this is the duration of the exercise, as the increase in PMNs was found only in protocols involving longer periods (see Table 1(a)). Cellular infiltration was found to be due to cold or chlorine. The role of exercise training is difficult to assess, given that the studies were conducted almost exclusively in trained subjects. We must add to this the reported changes in soluble inflammatory mediators. As a whole, these could be an expression of an asymptomatic acute inflammatory process similar to that observed in other tissues (muscle tissue). This would happen in a self-limiting way whenever the necessary conditions of time, environmental factors, and intensity are encountered. 


\section{Chronic Exercise-Induced Lung Inflammation}

Studies in animals have shown that training during $120 \mathrm{~min} / \mathrm{d}$ for a week on treadmill at $25 \mathrm{~m} / \mathrm{min}$ increases the expression of mRNA to tumor necrosis factor-alpha (TNF- $\alpha$ ) together with promoting a decrease of interferon gamma in pulmonary tissue samples [127]. Chimenti et al. [120] trained mice at moderate intensity for 6 weeks $(5 \mathrm{~d} /$ week), showing leukocyte infiltration in the airway. At this level of epithelia, an increase of apoptosis and a decrease of the ciliated cells were also observed. In mice that trained $60 \mathrm{~min} / \mathrm{d}$ to $50 \% \mathrm{~V}_{\max }$ for 24 weeks ( $5 \mathrm{~d} /$ week), no variation was observed in the number of macrophages in BALF, but it was possible to see a decrease of the capacity of these cells to form free radicals [126]. However, it is possible that the elaboration of training programs at moderate intensity $\left(66 \% \mathrm{VO}_{2} \max \right)$ generates a reduction of the inflammatory response after the completion of ischemia and pulmonary reperfusion, which was evidenced as a decrease of the release of interleukin $1 \beta$ and tumor necrosis factor-alpha (TNF- $\alpha$ ) at plasmatic level in a model performed in rats [129]. An analogous result was described by Toledo et al. [126], who did not find differences in TNF- $\alpha$, interleukin 10 , monocyte chemotactic protein, and interleukin 1 receptor antagonist, quantified in lung sections of mice, after training to $50 \% \mathrm{~V}_{\max }$ for $1 \mathrm{~h} /$ day, 5 days per week, for 24 weeks.

In studies conducted in humans, it has been reported that the participation in a long distance race training program over the course of a year generates a persistent inflammatory process with no apparent clinical repercussion and an increase in PMNs and in IL-8 concentrations, leukotriene $\mathrm{E}_{4}$, and histamine in the supernatant of induced sputum samples [130]. Subjects who participated in high performance athletic training in sessions of $1 \mathrm{~h} /$ day for 10 days, interspersed with rest 5 days, had lower $\mathrm{pH}$ values in $\mathrm{EBC}$ compared to healthy control subjects [98]. The same result in this parameter was reported in runners by Greenwald et al. [128]. In the same direction, in amateur runners $(\sim 50 \mathrm{~km} /$ week $)$ low levels of $\mathrm{pH}$ were reported compared to values of healthy control subjects [52]. High performance pool swimmers showed no differences in basal inflammatory parameters when compared with non-pool-based athletes; however, the analysis of the subgroup of athletes that had a positive result in the voluntary hyperventilation test (exercise-induced bronchial hyperreactivity indicator) presented a higher concentration of eNO and a higher count of eosinophils and of epithelial cells when compared to the group that had negative results on this test [102]; among other factors, this could be related to the number of years of practice of pool swimming, since no differences in eNO, in $\mathrm{EBC} \mathrm{pH}$, and in cellularity of induced sputum in adolescents were found when compared to normal subjects [131]. Elite swimmers, who trained between 800 and $3380 \mathrm{~km} /$ year, had more eosinophils and PMNs in induced sputum compared to nonathlete control subjects [99]. The cessation of the training for 3 months of swimmers decreases eosinophils and lymphocytes in induced sputum compared to active swimmers ( 1870 km/year) [100]. The comparison between healthy athletes who are swimmers and others who are engaged in land exercise has shown an increased number of PMNs in induced sputum samples [96]; the same comparison showed no differences in PMNs and eosinophils in induced sputum [102]. Chronic inflammation can be associated with pulmonary epithelial damage; thus, increases of clear cell protein (CC16) in plasma of swimmers who trained during 20 weeks in a chlorinated pool have been reported [132].

In skiers, who trained $435 \mathrm{~h} /$ year, increase of lymphocytes and mast cells has been found, with no differences in the concentration of TNF- $\alpha$ and myeloperoxidase in BALF compared to nonathlete control subjects [103]. Karjalainen et al. [101] reported, through the study of bronchial biopsies, an increase in neutrophils, eosinophils, macrophages, and $\mathrm{T}$ lymphocytes in elite skiers ( $435 \mathrm{~h} /$ year) compared to healthy control subjects, along with air tract remodeling indicators as an increase in collagen I and collagen III deposits in the submucosa, a hyperplasia of racket cells, and a higher expression of type 5 mucin. The use of anti-inflammatories (800 micrograms/day of budesonide) by cross-country elite skiers ( $\sim 27 \mathrm{~h} /$ year) during 20 weeks did not generate differences regarding the placebo $(\sim 468 \mathrm{~h} /$ year $)$ in the cellularity (PMNs, macrophages, lymphocytes, eosinophils, and mast cells), studied in BALF and in endobronchial biopsy [104].

In summary, animal models of physical training show increases of soluble inflammatory mediators, which include TNF- $\alpha$. Human studies have focused on subjects who have greater contact with irritants in the airway due to the specificity of their sport, whether runners (large ventilation volumes), skiers (cold), or swimmers (chlorine gas in the pool room). In these subjects, permanent tissue infiltration of granulocytes, macrophages, and lymphocytes has been observed. Evidence of these changes has been found in both noninvasive samples, such as induced sputum, and in biopsies in the bronchial region. At the same time, an increased presence of soluble proinflammatory substances has been reported. Overall, this suggests that these athletes in particular may suffer from persistent changes in tissue (chronic inflammation and airway remodeling) that have been associated with pulmonary symptoms and functional changes (see the bottom of Figure 1).

\section{Oxidative Damage and Inflammation, Relations, and Potential Effects}

The generation of prooxidant substances and the establishment of tissue oxidative damage are closely associated with inflammatory processes; thus, inflammatory cells are a known source of prooxidants derived from both oxygen and nitrogen [133]. At the same time, the increase of prooxidants has been involved in the intracellular signaling which leads to inflammatory cell activation, increased secretion of soluble mediators of inflammation [134], endothelial activation, and also increased expression of adhesion molecules and endothelial permeability [135]. This relation implies that, in many situations, the increase of prooxidants participates in the activation of inflammation and vice versa, demonstrating the close relationship between both phenomena [134]. 
The establishment of both oxidative damage and inflammation in the lungs has been involved in the origin/evolution of various pathological states; for example, both phenomena are a fundamental part of adult respiratory distress [136], asthma [137], chronic obstructive pulmonary disease [138], pulmonary hypertension [139], and viral infectious processes [140]. In the lungs, the relationship between oxidative changes and inflammation has rarely been studied as a main goal, but it is presumed that, in view of the studies conducted in other organs, it must be closely related. This is particularly important in subjects practicing sport, as both inflammation damage and oxidative damage have been implicated in the pathogenesis of phenomena of high prevalence in athletes such as rhinitis, bronchial hyperreactivity, asthma, and airway remodeling $[27,141]$; so, most respiratory symptoms (coughing, wheezing, breathlessness, and chest tightness) in endurance athletes such as cross-country skiers are known [142]. In addition, cross-country skiers show a presence of PMNs and lymphocytes infiltration in the airways [101]. This phenomenon can also be extrapolated to other endurance athletes [143] such as marathon runners, cyclists, and swimmers, the latter of which are also exposed to the chlorine in swimming pools, which could be one of the main factors inducing increased eosinophils and leukocytes in the sputum.

\section{Methods for the Study of Lung Inflammation/Oxidative Damage by Exercise}

The study of the oxidative/inflammatory damage in the lungs is challenging due to both anatomic functional limitations and the limitations of currently applied techniques. Current evidence on this topic focuses primarily on the study of lung diseases, while studies on the effect of exercise as a trigger effect of this phenomenon in healthy people are scarce. Summarizing what is known to date for the species analyzed, the determinations made and the samples obtained are shown in Tables 1 and 2. Lung tissue microenvironment has challenged developers of study methodologies, so, although systemic markers have been proposed (CC16, surfactant proteins $A$ and B, and Krebs von den Lungen-6), they do not yet have sufficient capacity to indicate minor damage, which implies that the processes of the lung itself cannot always be ascertained. For this reason, it is preferable to test samples originated from the lung; those currently under study are exhaled breath (whether direct or condensate), fluids (BALF, induced sputum, and nasal lavage), and cells and portions of whole tissue (biopsies, tissue homogenates, and cut pieces of tissue). Unfortunately, today there is still much controversy regarding the interpretation of the results obtained with these methods. In relation to oxidative/inflammatory exercise phenomenon, in animals, exhaled breath [112], lung tissue homogenates [113, 114, 117, 118, 120, 121, 127], bronchoalveolar lavage [121, 126], and lung tissue sections [126] have been used. In humans, most methods are focused on noninvasive methods and, among these, the induced sputum is the most widely used $[40,56,57,62,63,78,81,93,96,99,100,102$,
144]. Another sample studied corresponds to exhaled breath, which was analyzed whether directly $[56,57,59,65,71,75$, $81,89,97,102]$ or after being condensed at low temperature $[46,53,65,72-74,77,79,81,83,84,128,139]$. Very few studies have used bronchoalveolar lavage $[32,103,104]$ and lung tissue obtained by endobronchial biopsy [101, 104].

\section{Discussion}

In summary, we found that in acute exercise (see Tables 1(a) and 2(a)) there is more evidence of changes in cellularity (predominantly granulocytes) when it (was) is a prolonged highintensity exercise. This change was not so evident in animals; however, this should be resolved in further studies because it is a parameter measured recently in this population. Longterm of acute moderate exercise ( $>60 \mathrm{~min}$ ) in humans stimulated an increase of pulmonary inflammatory mediators (IL$8, \mathrm{LTB}_{4}$, and $\left.\mathrm{LTE}_{4}\right)$. Now, regarding prooxidants, a systematic increase in humans is observed after more than thirty minutes of exercise. It is noteworthy that, in acute exercise in animals, reports of an increase in lung lipid peroxidation are the majority, while it has not been observed in humans, except for intense exercise at high altitudes. This may be partially explained by the techniques used: while tissue samples were analyzed in animals, EBC samples were analyzed in humans; in another aspect, the change with greater support in relation to the enzymatic activity corresponds to the maintenance or decreased levels of GSH-Px and to the increase in SOD.

With regard to chronic exercise (training) and its effects (see Tables 1(b) and 2(b)), the number of studies is still very small, but there is a tendency observed, seen in humans, towards changes in cellularity compatible with chronic inflammation of the airways, particularly in subjects exposed to cold and chlorine. In animals, changes in pulmonary cellularity (leukocyte infiltration) were observed in only one study [120]. For soluble inflammatory mediators, in animals the scientific evidence has shown an increase in the concentration of these substances (IL4, IL6, and mRNA TNF- $\alpha$ ) subsequent to chronic exercise. The oxidative damage was observed in animals following moderate chronic exercise ( $>4$ sem), specifically in older rats, and cold or altitude environment. In humans, only one study showed oxidative damage by altitude training [45, 47]. With regard to enzymatic antioxidants, a tendency towards higher levels in SOD and GSH-Px is observed in humans. As for nonenzymatic antioxidants, only one study showed a decrease in the concentration of pulmonary GSH in trained rats [119].

The problem requires further study to clarify numerous questions in order to have a more definitive overview; thus, several challenges for researchers in the field have arisen. Likewise, the activity of the sources of production of free radicals in the lung (mitochondria, xanthine oxidase, $\mathrm{NADH}$ oxidase, and NOS) should be studied and the knowledge of the status of antioxidant systems, particularly in humans, where there are no records available, should be improved. Regarding inflammatory parameters, the study of soluble mediators of inflammation should be extended; in addition, the effect of both substances with antioxidant and 
anti-inflammatory effect should be explored. Furthermore, it is necessary to generate research projects which explore the parameters of oxidative/inflammatory mechanisms simultaneously in order to establish the interrelation mechanisms between both processes. It is also necessary to characterize the effect of time and intensity of performed exercise, the role of environmental conditions, and the level of training of the subjects on oxidative damage/lung inflammation by exercise. Finally, to advance the resolution of this problem, it is urgent to improve the technical conditions to allow obtaining representative samples of lung environment in its different compartments, and it is also necessary for these methods to be noninvasive and contribute to monitoring the athletes.

\section{Conflict of Interests}

The authors have no conflict of interests to declare.

\section{Acknowledgments}

The authors are grateful to Cristopher Evans for language assistance. This study is funded by Fondo de Ayuda a la Investigación (FAI), Universidad de los Andes, Project INOGTO2013, and the National Fund for Scientific \& Technological Development (FONDECYT), Project no. 11130082 granted to O. F. Araneda.

\section{References}

[1] L. Rokitzki, E. Logemann, A. N. Sagredos, M. Murphy, W. Wetzel-Rothl, and J. Keul, "Lipid peroxidation and antioxidative vitamins under extreme endurance stress," Acta Physiologica Scandinavica, vol. 150, no. 5, pp. 149-158, 1994.

[2] J. M. McBride, W. J. Kraemer, T. Triplett-McBride, and W. Sebastianelli, "Effect of resistance exercise on free radical production," Medicine and Science in Sports and Exercise, vol. 30, no. 1, pp. 67-72, 1998.

[3] D. P. Jones, "Redefining oxidative stress," Antioxidants \& Redox Signaling, vol. 8, no. 9-10, pp. 1865-1879, 2006.

[4] U. K. Şentürk, F. Gündüz, O. Kuru et al., "Exercise-induced oxidative stress leads hemolysis in sedentary but not trained humans," Journal of Applied Physiology, vol. 99, no. 4, pp. 14341441, 2005.

[5] L. Chimenti, G. Morici, A. Paternò et al., "Bronchial epithelial damage after a half-marathon in nonasthmatic amateur runners," The American Journal of Physiology-Lung Cellular and Molecular Physiology, vol. 298, no. 6, pp. L857-L862, 2010.

[6] G. Lippi, F. Schena, G. L. Salvagno, R. Aloe, G. Banfi, and G. C. Guidi, "Foot-strike haemolysis after a 60-km ultramarathon," Blood Transfusion, vol. 10, no. 3, pp. 377-383, 2012.

[7] A. Matsumoto, S. R. Mason, T. Flatscher-Bader et al., "Effects of exercise and antioxidant supplementation on endothelial gene expression," International Journal of Cardiology, vol. 158, no. 1, pp. 59-65, 2012.

[8] L. A. Silva, C. B. Tromm, G. Da Rosa et al., "Creatine supplementation does not decrease oxidative stress and inflammation in skeletal muscle after eccentric exercise," Journal of Sports Sciences, vol. 31, no. 11, pp. 1164-1176, 2013.
[9] D. A. McCarthy and M. M. Dale, "The leucocytosis of exercise. A review and model," Sports Medicine, vol. 6, no. 6, pp. 333-363, 1988.

[10] G. Camus, J. Pincemail, M. Ledent et al., "Plasma levels of polymorphonuclear elastase and myeloperoxidase after uphill walking and downhill running at similar energy cost," International Journal of Sports Medicine, vol. 13, no. 6, pp. 443-446, 1992.

[11] A. M. Niess, F. Passek, I. Lorenz et al., "Expression of the antioxidant stress protein heme oxygenase-1 (HO-1) in human leukocytes: acute and adaptational responses to endurance exercise," Free Radical Biology and Medicine, vol. 26, no. 1-2, pp. 184-192, 1999.

[12] A. M. Niess, H.-H. Dickhuth, H. Northoff, and E. Fehrenbach, "Free radicals and oxidative stress in exercise-immunological aspects," Exercise Immunology Review, vol. 5, pp. 22-56, 1999.

[13] N. Kirschvink, N. Smith, L. Fiévez et al., "Effect of chronic airway inflammation and exercise on pulmonary and systemic antioxidant status of healthy and heaves-affected horses," Equine Veterinary Journal, vol. 34, no. 6, pp. 563-571, 2002.

[14] E. C. Gomes, V. Stone, and G. Florida-James, "Impact of heat and pollution on oxidative stress and CC16 secretion after $8 \mathrm{~km}$ run," European Journal of Applied Physiology, vol. 111, no. 9, pp. 2089-2097, 2011.

[15] C. T. Reis Gonçalves, C. G. Reis Gonçalves, F. M. de Almeida et al., "Protective effects of aerobic exercise on acute lung injury induced by LPS in mice," Critical Care, vol. 16, no. 5, article R199, 2012.

[16] J. H. Roum, R. Buhl, N. G. McElvaney, Z. Borok, and R. G. Crystal, "Systemic deficiency of glutathione in cystic fibrosis," Journal of Applied Physiology, vol. 75, no. 6, pp. 2419-2424, 1993.

[17] R. K. Brown, H. Wyatt, J. F. Price, and F. J. Kelly, "Pulmonary dysfunction in cystic fibrosis is associated with oxidative stress," The European Respiratory Journal, vol. 9, no. 2, pp. 334-339, 1996.

[18] S. A. Peters and F. J. Kelly, "Vitamin E supplementation in cystic fibrosis," Journal of Pediatric Gastroenterology and Nutrition, vol. 22, no. 4, pp. 341-345, 1996.

[19] I. Rahman and W. MacNee, "Lung glutathione and oxidative stress: implications in cigarette smoke-induced airway disease," The American Journal of Physiology-Lung Cellular and Molecular Physiology, vol. 277, no. 6, pp. L1067-L1088, 1999.

[20] I. Rahman and W. MacNee, "Oxidative stress and regulation of glutathione in lung inflammation," The European Respiratory Journal, vol. 16, no. 3, pp. 534-554, 2000.

[21] T. S. Hallstrand, E. Calenoff, J. W. Becker, W. R. Henderson Jr., and M. L. Aitken, "The role of allergy in manifestations of respiratory disease in adult cystic fibrosis," Annals of Allergy, Asthma \& Immunology, vol. 92, no. 2, pp. 228-233, 2004.

[22] I. Rahman, S. K. Biswas, and A. Kode, "Oxidant and antioxidant balance in the airways and airway diseases," European Journal of Pharmacology, vol. 533, no. 1-3, pp. 222-239, 2006.

[23] J. M. Weiler, S. Bonini, R. Coifman et al., "American Academy of Allergy, Asthma \& Immunology Work Group report: exerciseinduced asthma," The Journal of allergy and clinical immunology, vol. 119, no. 6, pp. 1349-1358, 2007.

[24] J. P. Parsons, C. P. Baran, G. Phillips et al., "Airway inflammation in exercise-induced bronchospasm occurring in athletes without asthma," The Journal of Asthma, vol. 45, no. 5, pp. 363-367, 2008 
[25] F. Holguin and A. Fitzpatrick, "Obesity, asthma, and oxidative stress," Journal of Applied Physiology, vol. 108, no. 3, pp. 754-759, 2010.

[26] B. M. Fischer, E. Pavlisko, and J. A. Voynow, "Pathogenic triad in COPD: oxidative stress, protease-antiprotease imbalance, and inflammation," International Journal of Chronic Obstructive Pulmonary Disease, vol. 6, no. 1, pp. 413-421, 2011.

[27] K. D. Fitch, "An overview of asthma and airway hyperresponsiveness in Olympic athletes," British Journal of Sports Medicine, vol. 46, no. 6, pp. 413-416, 2012.

[28] K. J. Burnham, T. J. Arai, D. J. Dubowitz et al., "Pulmonary perfusion heterogeneity is increased by sustained, heavy exercise in humans," Journal of Applied Physiology, vol. 107, no. 5, pp. 15591568, 2009.

[29] K. C. Beck, B. D. Johnson, T. P. Olson, and T. A. Wilson, "Ventilation-perfusion distribution in normal subjects," Journal of Applied Physiology, vol. 113, no. 6, pp. 872-877, 2012.

[30] A. N. Freed and M. S. Davis, "Hyperventilation with dry air increases airway surface fluid osmolality in canine peripheral airways," American Journal of Respiratory and Critical Care Medicine, vol. 159, no. 4, part 1, pp. 1101-1107, 1999.

[31] E. R. McFadden Jr. and B. M. Pichurko, "Intraairway thermal profiles during exercise and hyperventilation in normal man," The Journal of Clinical Investigation, vol. 76, no. 3, pp. 1007-1010, 1985.

[32] K. Larsson, G. Tornling, D. Gavhed, C. Müller-Suur, and L. Palmberg, "Inhalation of cold air increases the number of inflammatory cells in the lungs in healthy subjects," The European Respiratory Journal, vol. 12, no. 4, pp. 825-830, 1998.

[33] A. Kendall, L. Hoffman-Goetz, M. Houston, B. MacNeil, and Y. Arumugam, "Exercise and blood lymphocyte subset responses: intensity, duration, and subject fitness effects," Journal of Applied Physiology, vol. 69, no. 1, pp. 251-260, 1990.

[34] D. C. Nieman, L. M. Johanssen, J. W. Lee, and K. Arabatzis, "Infectious episodes in runners before and after the Los Angeles Marathon," Journal of Sports Medicine and Physical Fitness, vol. 30, no. 3, pp. 316-328, 1990.

[35] G. W. Heath, E. S. Ford, T. E. Craven, C. A. Macera, K. L. Jackson, and R. R. Pate, "Exercise and the incidence of upper respiratory tract infections," Medicine and Science in Sports and Exercise, vol. 23, no. 2, pp. 152-157, 1991.

[36] D. C. Nieman, L. M. Onasch, and J. W. Lee, "The effects of moderate exercise training on nutrient intake in mildly obese women," Journal of the American Dietetic Association, vol. 90, no. 11, pp. 1557-1562, 1990.

[37] D. C. Nieman, D. A. Henson, G. Gusewitch et al., "Physical activity and immune function in elderly women," Medicine and Science in Sports and Exercise, vol. 25, no. 7, pp. 823-831, 1993.

[38] S. D. Anderson, R. E. Schoeffel, R. Follet, C. P. Perry, E. Daviskas, and M. Kendall, "Sensitivity to heat and water loss at rest and during exercise in asthmatic patients," European Journal of Respiratory Diseases, vol. 63, no. 5, pp. 459-471, 1982.

[39] S. D. Anderson and P. Kippelen, "Exercise-induced bronchoconstriction: pathogenesis," Current Allergy and Asthma Reports, vol. 5, no. 2, pp. 116-122, 2005.

[40] L. Chimenti, G. Morici, A. Paternò et al., "Environmental conditions, air pollutants, and airway cells in runners: a longitudinal field study," Journal of Sports Sciences, vol. 27, no. 9, pp. 925-935, 2009.

[41] P. L. Kinney, D. M. Nilsen, M. Lippmann et al., "Biomarkers of lung inflammation in recreational joggers exposed to ozone,"
American Journal of Respiratory and Critical Care Medicine, vol. 154, no. 5, pp. 1430-1435, 1996.

[42] C. C. Daigle, D. C. Chalupa, F. R. Gibb et al., "Ultrafine particle deposition in humans during rest and exercise," Inhalation Toxicology, vol. 15, no. 6, pp. 539-552, 2003.

[43] N. D. Magnani, T. Marchini, D. R. Tasat, S. Alvarez, and P. A. Evelson, "Lung oxidative metabolism after exposure to ambient particles," Biochemical and Biophysical Research Communications, vol. 412, no. 4, pp. 667-672, 2011.

[44] F. Farina, G. Sancini, C. Battaglia et al., "Milano summer particulate matter (PM10) triggers lung inflammation and extra pulmonary adverse events in mic," PLoS ONE, vol. 8, no. 2, Article ID e56636, 2013.

[45] S. Wittkopp, N. Staimer, T. Tjoa et al., "Mitochondrial genetic background modifies the relationship between traffic-related air pollution exposure and systemic biomarkers of inflammation," PLoS ONE, vol. 8, no. 5, Article ID e64444, 2013.

[46] O. F. Araneda, C. García, N. Lagos et al., "Lung oxidative stress as related to exercise and altitude. Lipid peroxidation evidence in exhaled breath condensate: a possible predictor of acute mountain sickness," European Journal of Applied Physiology, vol. 95, no. 5-6, pp. 383-390, 2005.

[47] I. Heinicke, A. Boehler, T. Rechsteiner et al., "Moderate altitude but not additional endurance training increases markers of oxidative stress in exhaled breath condensate," European Journal of Applied Physiology, vol. 106, no. 4, pp. 599-604, 2009.

[48] A. J. Carlisle and N. C. C. Sharp, "Exercise and outdoor ambient air pollution," British Journal of Sports Medicine, vol. 35, no. 4, pp. 214-222, 2001.

[49] I. S. Mudway and F. J. Kelly, "An investigation of inhaled ozone dose and the magnitude of airway inflammation in healthy adults," American Journal of Respiratory and Critical Care Medicine, vol. 169, no. 10, pp. 1089-1095, 2004.

[50] H. Adachi, P. H. Nguyen, R. Belardinelli, D. Hunter, T. Sung, and K. Wasserman, "Nitric oxide production during exercise in chronic heart failure," American Heart Journal, vol. 134, no. 2, pp. 196-202, 1997.

[51] P. Agostoni and M. Bussotti, "Exhaled nitric oxide and exercise performance in heart failure," Archives of Physiology and Biochemistry, vol. 111, no. 4, pp. 293-296, 2003.

[52] O. F. Araneda, A. J. Guevara, C. Contreras, N. Lagos, and F. J. Berral, "Exhaled breath condensate analysis after long distance races," International Journal of Sports Medicine, vol. 33, no. 12, pp. 955-961, 2012.

[53] O. F. Araneda, R. Urbina-Stagno, M. Tuesta et al., "Increase of pro-oxidants with no evidence of lipid peroxidation in exhaled breath condensate after a $10-\mathrm{km}$ race in non-athletes," Journal of Physiology and Biochemistry, vol. 70, no. 1, pp. 107-115, 2014.

[54] A. Bikov, R. Gajdócsi, É. Huszár et al., "Exercise inducedexercise increases exhaled breath condensate cysteinyl leukotriene concentration in asthmatic patients," Journal of Asthma, vol. 47, no. 9, pp. 1057-1062, 2010.

[55] A. Bikov, G. Galffy, L. Tamasi et al., "Exhaled breath condensate $\mathrm{pH}$ decreases during exercise-induced bronchoconstriction," Respirology, vol. 19, no. 4, pp. 563-569, 2014.

[56] M. R. Bonsignore, G. Morici, L. Riccobono et al., "Airway inflammation in nonasthmatic amateur runners," The American Journal of Physiology - Lung Cellular and Molecular Physiology, vol. 281, no. 3, pp. L668-L676, 2001.

[57] M. R. Bonsignore, G. Morici, L. Riccobono et al., "Airway cells after swimming outdoors or in the sea in nonasthmatic athletes," 
Medicine and Science in Sports and Exercise, vol. 35, no. 7, pp. 1146-1152, 2003.

[58] S. Carbonnelle, A. Bernard, I. R. Doyle, J. Grutters, and M. Francaux, "Fractional exhaled NO and serum pneumoproteins after swimming in a chlorinated pool," Medicine and Science in Sports and Exercise, vol. 40, no. 8, pp. 1472-1476, 2008.

[59] M. F. Chirpaz-Oddou, A. Favre-Juvin, P. Flore et al., "Nitric oxide response in exhaled air during an incremental exhaustive exercise," Journal of Applied Physiology, vol. 82, no. 4, pp. 13111318, 1997.

[60] E. Clini, L. Bianchi, M. Vitacca, R. Porta, K. Foglio, and N. Ambrosino, "Exhaled nitric oxide and exercise in stable COPD patients," Chest, vol. 117, no. 3, pp. 702-707, 2000.

[61] H. W. F. M. De Gouw, S. J. Marshall-Partridge, H. Van Der Veen, J. G. Van Den Aardweg, P. S. Hiemstra, and P. J. Sterk, "Role of nitric oxide in the airway response to exercise in healthy and asthmatic subjects," Journal of Applied Physiology, vol. 90, no. 2, pp. 586-592, 2001.

[62] M. Denguezli-Bouzgarrou, B. Sriha, I. Ben Cheikh, W. Ben Turkia, Z. Tabka, and A. Zbidi, "Effect of endurance exercise on airway cells in runners," Science \& Sports, vol. 21, no. 2, pp. 99-100, 2006.

[63] M. Denguezli-Bouzgarrou, H. Ben Saad, I. Ben Chiekh, S. Gaied, Z. Tabka, and A. Zbidi, "Role of lung inflammatory mediators as a cause of training-induced lung function changes in runners," Science \& Sports, vol. 22, no. 1, pp. 35-42, 2007.

[64] B. Evjenth, T. E. Hansen, and J. Holt, "Exhaled nitric oxide decreases during exercise in non-asthmatic children," The Clinical Respiratory Journal, vol. 7, no. 2, pp. 121-127, 2013.

[65] L. Font-Ribera, M. Kogevinas, J.-P. Zock et al., "Short-term changes in respiratory biomarkers after swimming in a chlorinated pool," Environmental Health Perspectives, vol. 118, no. 11, pp. 1538-1544, 2010.

[66] F. García-Río, M. Ramírez, O. Mediano et al., "Exhaled nitric oxide and airway caliber during exercise-induced bronchoconstriction," International Journal of Sports Medicine, vol. 27, no. 11, pp. 905-910, 2006.

[67] S. R. Hopkins, R. B. Schoene, W. R. Henderson, R. G. Spragg, T. R. Martin, and J. B. West, "Intense exercise impairs the integrity of the pulmonary blood-gas barrier in elite athletes," American Journal of Respiratory and Critical Care Medicine, vol. 155, no. 3 , pp. 1090-1094, 1997.

[68] P. Kippelen, C. Caillaud, E. Robert, K. Masmoudi, and C. Préfaut, "Exhaled nitric oxide level during and after heavy exercise in athletes with exercise-induced hypoxaemia," Pflugers Archiv, vol. 444, no. 3, pp. 397-404, 2002.

[69] S. L. Lovell, H. Stevenson, I. S. Young et al., "Exhaled nitric oxide during incremental and constant workload exercise in chronic cardiac failure," European Journal of Clinical Investigation, vol. 30, no. 3, pp. 181-187, 2000.

[70] K. J. Mantione, T. Esch, and G. B. Stefano, "Detection of nitric oxide in exhaled human breath: exercise and resting determinations," Medical Science Monitor, vol. 13, no. 3, pp. MT1-MT5, 2007.

[71] A. Matsumoto, Y. Hirata, S.-I. Momomura et al., "Increased nitric oxide production during exercise," The Lancet, vol. 343, no. 8901, pp. 849-850, 1994.

[72] E. Marek, K. Mückenhoff, H. J. Streckert, G. Becher, and W. Marek, "Measurements of L-lactate and $\mathrm{H}_{2} \mathrm{O}_{2}$ in exhaled breath condensate at rest and mild to moderate exercise in young and healthy subjects," Pneumologie, vol. 62, no. 9, pp. 541-547, 2008.
[73] E. Marek, P. Platen, J. Volke, K. Mückenhoff, and W. Marek, "Hydrogen peroxide release and acid-base status in exhaled breath condensate at rest and after maximal exercise in young, healthy subjects," European Journal of Medical Research, vol. 14, supplement 4, pp. 134-139, 2009.

[74] E. Marek, J. Volke, K. Mückenhoff, P. Platen, and W. Marek, "Exercise in cold air and hydrogen peroxide release in exhaled breath condensate," Advances in Experimental Medicine and Biology, vol. 756, pp. 169-177, 2013.

[75] M. J. Maroun, S. Mehta, R. Turcotte, M. G. Cosio, and S. N. A. Hussain, "Effects of physical conditioning on endogenous nitric oxide output during exercise," Journal of Applied Physiology, vol. 79, no. 4, pp. 1219-1225, 1995.

[76] E. M. Mercken, G. J. Hageman, A. M. W. J. Schols, M. A. Akkermans, A. Bast, and E. F. M. Wouters, "Rehabilitation decreases exercise-induced oxidative stress in chronic obstructive pulmonary disease," American Journal of Respiratory and Critical Care Medicine, vol. 172, no. 8, pp. 994-1001, 2005.

[77] E. M. Mercken, H. R. Gosker, E. P. Rutten et al., "Systemic and pulmonary oxidative stress after single-leg exercise in COPD," Chest, vol. 136, no. 5, pp. 1291-1300, 2009.

[78] G. Morici, M. R. Bonsignore, D. Zangla et al., "Airway cell composition at rest and after an all-out test in competitive rowers," Medicine and Science in Sports and Exercise, vol. 36, no. 10, pp. 1723-1729, 2004.

[79] D. Nowak, S. Kalucka, P. Bialasiewicz, and M. Król, "Exhalation of $\mathrm{H}_{2} \mathrm{O}_{2}$ and thiobarbituric acid reactive substances (TBARs) by healthy subjects," Free Radical Biology \& Medicine, vol. 30, no. 2, pp. 178-186, 2001.

[80] P. Nadziakiewicz, P. Knapik, D. Ziora, and D. Nowak, “Moderate exercise decreases nitric oxide exhalation in patients with stable coronary artery disease," Journal of Physiology and Pharmacology, vol. 57, supplement 4, pp. 213-221, 2006.

[81] L. Pedersen, T. K. Lund, E. Mølgaard, S. A. Kharitonov, P. J. Barnes, and V. Backer, "The acute effect of swimming on airway inflammation in adolescent elite swimmers," The Journal of Allergy and Clinical Immunology, vol. 123, no. 2, pp. 502-504, 2009.

[82] S. Pogliaghi, J. A. Krasney, and D. R. Pendergast, "Effect of gravity on lung exhaled nitric oxide at rest and during exercise," Respiration Physiology, vol. 107, no. 2, pp. 157-164, 1997.

[83] J. M. Pucsok, I. Györe, K. Argay et al., "Effect of exercise on levels of cyclo-oxygenase mediators in exhaled breath condensate in elite athletes," The Journal of Sports Medicine and Physical Fitness, vol. 47, no. 2, pp. 223-227, 2007.

[84] M. Riediker and B. Danuser, "Exhaled breath condensate $\mathrm{pH}$ is increased after moderate exercise," Journal of Aerosol Medicine: Deposition, Clearance, and Effects in the Lung, vol. 20, no. 1, pp. 13-18, 2007.

[85] M. S. Riley, J. Pórszász, J. Miranda, M. P. K. J. Engelen, B. Brundage, and K. Wasserman, "Exhaled nitric oxide during exercise in primary pulmonary hypertension and pulmonary fibrosis," Chest, vol. 111, no. 1, pp. 44-50, 1997.

[86] G. Rolla, L. Mangiardi, C. Bucca et al., "Exhaled nitric oxide during exercise and dobutamine stress echocardiography in patients with mitral stenosis," European Journal of Internal Medicine, vol. 14, no. 3, pp. 166-171, 2003.

[87] H.-W. Shin, C. M. Rose-Gottron, D. M. Cooper, M. Hill, and S. C. George, "Impact of high-intensity exercise on nitric oxide exchange in healthy adults," Medicine and Science in Sports and Exercise, vol. 35, no. 6, pp. 995-1003, 2003. 
[88] C. M. St Croix, T. J. Wetter, D. F. Pegelow, K. C. Meyer, and J. A. Dempsey, "Assessment of nitric oxide formation during exercise," American Journal of Respiratory and Critical Care Medicine, vol. 159, no. 4, part 1, pp. 1125-1133, 1999.

[89] A. Therminarias, M. F. Oddou, A. Favre-Juvin, P. Flore, and M. Delaire, "Bronchial obstruction and exhaled nitric oxide response during exercise in cold air," European Respiratory Journal, vol. 12, no. 5, pp. 1040-1045, 1998.

[90] G. Trolin, T. Anden, and G. Hedenstierna, "Nitric oxide (NO) in expired air at rest and during exercise," Acta Physiologica Scandinavica, vol. 150, no. 5, pp. 159-164, 1994.

[91] E. Tufvesson, H. Svensson, J. Ankerst, and L. Bjermer, "Increase of club cell (Clara) protein (CC16) in plasma and urine after exercise challenge in asthmatics and healthy controls, and correlations to exhaled breath temperature and exhaled nitric oxide," Respiratory Medicine, vol. 107, no. 11, pp. 1675-1681, 2013.

[92] S. Verges, J. Tonini, P. Flore, A. Favre-Juvin, P. Lévy, and B. Wuyam, "Exhaled nitric oxide in single and repetitive prolonged exercise," Journal of Sports Sciences, vol. 24, no. 11, pp. 1157-1163, 2006.

[93] T. J. Wetter, Z. Xiang, D. A. Sonetti et al., "Role of lung inflammatory mediators as a cause of exercise-induced arterial hypoxemia in young athletes," Journal of Applied Physiology, vol. 93, no. 1, pp. 116-126, 2002.

[94] Y. Yasuda, T. Itoh, M. Miyamura, and H. Nishino, "Comparison of exhaled nitric oxide and cardiorespiratory indices between nasal and oral breathing during submaximal exercise in humans," The Japanese Journal of Physiology, vol. 47, no. 5, pp. 465-470, 1997.

[95] Z. Zietkowski, R. Skiepko, M. M. Tomasiak-Lozowska, B. Mroczko, M. Szmitkowski, and A. Bodzenta-Lukaszyk, "Changes in high-sensitivity C-reactive protein in serum and exhaled breath condensate after intensive exercise in patients with allergic asthma," International Archives of Allergy and Immunology, vol. 153, no. 1, pp. 75-85, 2010.

[96] J. Belda, S. Ricart, P. Casan et al., "Airway inflammation in the elite athlete and type of sport," British Journal of Sports Medicine, vol. 42, no. 4, pp. 244-249, 2008.

[97] S. Carraro, M. F. Pasquale, M. Da Frè et al., "Swimming pool attendance and exhaled nitric oxide in children," The Journal of Allergy and Clinical Immunology, vol. 118, no. 4, pp. 958-960, 2006.

[98] J. M. Ferdinands, C. A. G. Crawford, R. Greenwald, D. Van Sickle, E. Hunter, and W. G. Teague, "Breath acidification in adolescent runners exposed to atmospheric pollution: a prospective, repeated measures observational study," Environmental Health: A Global Access Science Source, vol. 7, article 10, 2008.

[99] I. J. Helenius, P. Rytilä, T. Metso, T. Haahtela, P. Venge, and H. O. Tikkanen, "Respiratory symptoms, bronchial responsiveness, and cellular characteristics of induced sputum in elite swimmers," Allergy, vol. 53, no. 4, pp. 346-352, 1998.

[100] I. Helenius, P. Rytilä, S. Sarna et al., "Effect of continuing or finishing high-level sports on airway inflammation, bronchial hyperresponsiveness, and asthma: a 5-year prospective followup study of 42 highly trained swimmers," The Journal of Allergy and Clinical Immunology, vol. 109, no. 6, pp. 962-968, 2002.

[101] E.-M. Karjalainen, A. Laitinen, M. Sue-Chu, A. Altraja, L. Bjermer, and L. A. Laitinen, "Evidence of airway inflammation and remodeling in ski athletes with and without bronchial hyperresponsiveness to methacholine," American Journal of
Respiratory and Critical Care Medicine, vol. 161, no. 6, pp. 20862091, 2000.

[102] N. Martin, M. R. Lindley, B. Hargadon, W. R. Monteiro, and I. D. Pavord, "Airway dysfunction and inflammation in pool-and non-pool-based elite athletes," Medicine and Science in Sports and Exercise, vol. 44, no. 8, pp. 1433-1439, 2012.

[103] M. Sue-Chu, L. Larsson, T. Moen, S. I. Rennard, and L. Bjermer, "Bronchoscopy and bronchoalveolar lavage findings in crosscountry skiers with and without 'ski asthma,' The European Respiratory Journal, vol. 13, no. 3, pp. 626-632, 1999.

[104] M. Sue-Chu, E.-M. Karjalainen, A. Laitinen, L. Larsson, L. A. Laitinen, and L. Bjermer, "Placebo-controlled study of inhaled budesonide on indices of airway inflammation in bronchoalveolar lavage fluid and bronchial biopsies in cross-country skiers," Respiration, vol. 67, no. 4, pp. 417-425, 2000.

[105] M. Akil, U. Gurbuz, M. Bicer, I. Halifeoglu, A. K. Baltaci, and R. Mogulkoc, "Selenium prevents lipid peroxidation in liver and lung tissues of rats in acute swimming exercise," Bratislavské Lekárske Listy, vol. 116, no. 4, pp. 233-235, 2015.

[106] F. H. Al-Hashem, "Potential roles for vitamins E and C in combination in modulating exhaustive swimming and high altitudeassociated lung injury in rats," Saudi Medical Journal, vol. 33, no. 4, pp. 367-374, 2012.

[107] C. Caillaud, G. Py, N. Eydoux, P. Legros, C. Prefaut, and J. Mercier, "Antioxidants and mitochondrial respiration in lung, diaphragm, and locomotor muscles: effect of exercise," Free Radical Biology \& Medicine, vol. 26, no. 9-10, pp. 1292-1299, 1999.

[108] M. P. Cathcart, S. Love, D. G. M. Sutton, R. J. M. Reardon, and K. J. Hughes, "The application of exhaled breath analysis in racing Thoroughbreds and the influence of high intensity exercise and ambient temperature on the concentration of carbon monoxide and pH in exhaled breath," Veterinary Journal, vol. 197, no. 2, pp. 318-323, 2013.

[109] H. Hatao, S. Oh-Ishi, M. Itoh et al., "Effects of acute exercise on lung antioxidant enzymes in young and old rats," Mechanisms of Ageing and Development, vol. 127, no. 4, pp. 384-390, 2006.

[110] C.-C. Huang, S.-C. Tsai, and W.-T. Lin, "Potential ergogenic effects of L-arginine against oxidative and inflammatory stress induced by acute exercise in aging rats," Experimental Gerontology, vol. 43, no. 6, pp. 571-577, 2008.

[111] W.-T. Lin, S.-C. Yang, K.-T. Chen, C.-C. Huang, and N.-Y. Lee, "Protective effects of L-arginine on pulmonary oxidative stress and antioxidant defenses during exhaustive exercise in rats," Acta Pharmacologica Sinica, vol. 26, no. 8, pp. 992-999, 2005.

[112] P. C. Mills, D. J. Marlin, E. Demoncheaux et al., "Nitric oxide and exercise in the horse," The Journal of Physiology, vol. 495, no. 3, pp. 863-874, 1996.

[113] Z. Radák, A. Nakamura, H. Nakamoto, K. Asano, H. Ohno, and S. Goto, "A period of anaerobic exercise increases the accumulation of reactive carbonyl derivatives in the lungs of rats," Pflügers Archiv: European Journal of Physiology, vol. 435, no. 3, pp. 439-441, 1998.

[114] K. V. Reddy, T. C. Kumar, M. Prasad, and P. Reddanna, "Pulmonary lipid peroxidation and antioxidant defenses during exhaustive physical exercise: the role of vitamin $\mathrm{E}$ and selenium," Nutrition, vol. 14, no. 5, pp. 448-451, 1998.

[115] M. Prigol, C. Luchese, and C. W. Nogueira, "Antioxidant effect of diphenyl diselenide on oxidative stress caused by acute physical exercise in skeletal muscle and lungs of mice," Cell Biochemistry and Function, vol. 27, no. 4, pp. 216-222, 2009. 
[116] S. E. Terblanche, "The effects of exhaustive exercise on the activity levels of catalase in various tissues of male and female rats," Cell Biology International, vol. 23, no. 11, pp. 749-753, 1999.

[117] M. Altan, P. Atukeren, M. Mengi, G. Metin, L. Cakar, and K. Gumustas, "Influence of intermittent hypobaric exposure on SOD and TBARS levels in trained rats," Chinese Journal of Physiology, vol. 52, no. 2, pp. 106-112, 2009.

[118] S. Asami, T. Hirano, R. Yamaguchi, Y. Tsurudome, H. Itoh, and H. Kasai, "Effects of forced and spontaneous exercise on 8hydroxydeoxyguanosine levels in rat organs," Biochemical and Biophysical Research Communications, vol. 243, no. 3, pp. 678682,1998

[119] C. Aydin, F. Sonat, S. K. Sahin, I. T. Cangul, and G. Ozkaya, "Long term dietary restriction ameliorates swimming exerciseinduced oxidative stress in brain and lung of middle-aged rat," Indian Journal of Experimental Biology, vol. 47, no. 1, pp. 24-31, 2009.

[120] L. Chimenti, G. Morici, A. Paternò et al., "Endurance training damages small airway epithelium in mice," American Journal of Respiratory and Critical Care Medicine, vol. 175, no. 5, pp. 442449, 2007.

[121] M. J. da Cunha, A. A. da Cunha, G. K. Ferreira et al., "The effect of exercise on the oxidative stress induced by experimental lung injury," Life Sciences, vol. 92, no. 3, pp. 218-227, 2013.

[122] F. Gündüz, Ü. K. Şentürk, O. Kuru, B. Aktekin, and M. R. Aktekin, "The effect of one year's swimming exercise on oxidant stress and antioxidant capacity in aged rats," Physiological Research, vol. 53, no. 2, pp. 171-176, 2004.

[123] N.-J. Lee, J.-W. Lee, J.-H. Sung, Y.-G. Ko, S. Hwang, and J.K. Kang, "Effects of administration of IH901, a ginsenoside intestinal metabolite, on muscular and pulmonary antioxidant functions after eccentric exercise," Journal of Veterinary Science, vol. 14, no. 3, pp. 249-256, 2013.

[124] B. T. Menegali, R. T. Nesi, P. S. Souza et al., "The effects of physical exercise on the cigarette smoke-induced pulmonary oxidative response," Pulmonary Pharmacology \& Therapeutics, vol. 22, no. 6, pp. 567-573, 2009.

[125] C. R. Olivo, E. N. Miyaji, M. L. S. Oliveira et al., "Aerobic exercise attenuates pulmonary inflammation induced by Streptococcus pneumoniae," Journal of Applied Physiology, vol. 117, no. 9, pp. 998-1007, 2014

[126] A. C. Toledo, R. M. Magalhaes, D. C. Hizume et al., "Aerobic exercise attenuates pulmonary injury induced by exposure to cigarette smoke," The European Respiratory Journal, vol. 39, no. 2, pp. 254-264, 2012.

[127] D. S. Yang, "Effects of strenuous exercise on expressions of inflammation-related cytokines of lung tissue in rats," International Journal of Infectious Diseases, vol. 15, pp. S106-S107, 2011.

[128] R. Greenwald, J. M. Ferdinands, and W. G. Teague, "Ionic determinants of exhaled breath condensate $\mathrm{pH}$ before and after exercise in adolescent athletes," Pediatric Pulmonology, vol. 44, no. 8, pp. 768-777, 2009.

[129] R. K. Mussi, E. A. Camargo, T. Ferreira et al., "Exercise training reduces pulmonary ischaemia-reperfusion-induced inflammatory responses," The European Respiratory Journal, vol. 31, no. 3, pp. 645-649, 2008

[130] M. Denguezli, I. Ben Chiekh, H. Ben Saad, M. Zaouali-Ajina, Z. Tabka, and A. Zbidi, "One-year endurance training: effects on lung function and airway inflammation," Journal of Sports Sciences, vol. 26, no. 12, pp. 1351-1359, 2008.

[131] L. Pedersen, T. K. Lund, P. J. Barnes, S. A. Kharitonov, and V. Backer, "Airway responsiveness and inflammation in adolescent elite swimmers," The Journal of Allergy and Clinical Immunology, vol. 122, no. 2, pp. 322-327.e1, 2008.

[132] Á. Fernández-Luna, L. Gallardo, M. Plaza-Carmona et al., "Respiratory function and changes in lung epithelium biomarkers after a short-training intervention in chlorinated vs. ozone indoor pools," PLoS ONE, vol. 8, no. 7, Article ID e68447, 2013.

[133] S. Bréchard and E. J. Tschirhart, "Regulation of superoxide production in neutrophils: role of calcium influx," Journal of Leukocyte Biology, vol. 84, no. 5, pp. 1223-1237, 2008.

[134] H. Lum and K. A. Roebuck, "Oxidant stress and endothelial cell dysfunction," American Journal of Physiology-Cell Physiology, vol. 280, no. 4, pp. C719-C741, 2001.

[135] R. Scalia and A. M. Lefer, "In vivo regulation of PECAM1 activity during acute endothelial dysfunction in the rat mesenteric microvasculature," Journal of Leukocyte Biology, vol. 64, no. 2, pp. 163-169, 1998.

[136] C. E. Cross, B. Frei, and S. Louie, "The adult respiratory distress syndrome (ARDS) and oxidative stress: therapeutic implications," Advances in Experimental Medicine and Biology, vol. 264, pp. 435-448, 1990.

[137] A. Ahmad, M. Shameem, and Q. Husain, "Relation of oxidantantioxidant imbalance with disease progression in patients with asthma," Annals of Thoracic Medicine, vol. 7, no. 4, pp. 226-232, 2012.

[138] G. Fisher, D. D. Schwartz, J. Quindry et al., "Lymphocyte enzymatic antioxidant responses to oxidative stress following high-intensity interval exercise," Journal of Applied Physiology, vol. 110, no. 3, pp. 730-737, 2011.

[139] O. F. Araneda and M. Tuesta, "Lung oxidative damage by hypoxia," Oxidative Medicine and Cellular Longevity, vol. 2012, Article ID 856918, 18 pages, 2012.

[140] S. Selemidis, H. J. Seow, B. R. S. Broughton et al., "Nox1 oxidase suppresses influenza a virus-induced lung inflammation and oxidative stress," PLoS ONE, vol. 8, no. 4, Article ID e60792, 2013.

[141] L.-P. Boulet, "Cough and upper airway disorders in elite athletes: a critical review," British Journal of Sports Medicine, vol. 46, no. 6, pp. 417-421, 2012.

[142] K. Larsson, P. Ohlsen, L. Larsson, P. Malmberg, P.-O. Rydstrom, and H. Ulriksen, "High prevalence of asthma in cross country skiers," British Medical Journal, vol. 307, no. 6915, pp. 1326-1329, 1993.

[143] M. Sue-Chu, "Winter sports athletes: long-term effects of cold air exposure," British Journal of Sports Medicine, vol. 46, no. 6, pp. 397-401, 2012.

[144] L.-P. Boulet, H. Turcotte, J.-B. Langdeau, and M.-C. Bernier, "Lower airway inflammatory responses to high-intensity training in athletes," Clinical and Investigative Medicine, vol. 28, no. 1, pp. 15-22, 2005. 


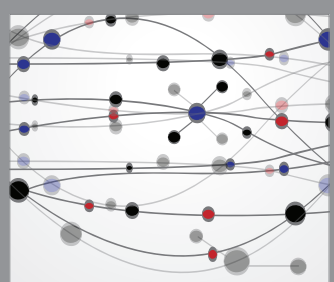

The Scientific World Journal
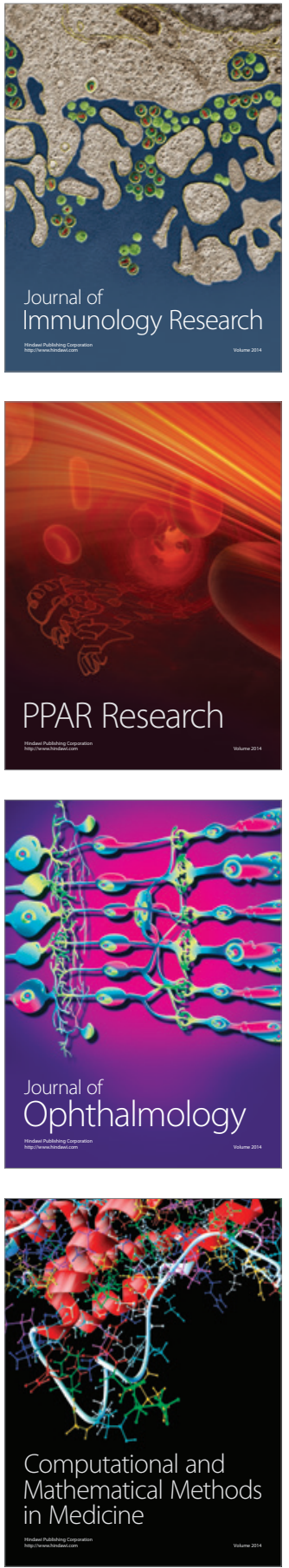

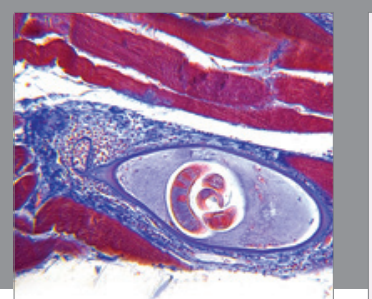

Gastroenterology Research and Practice

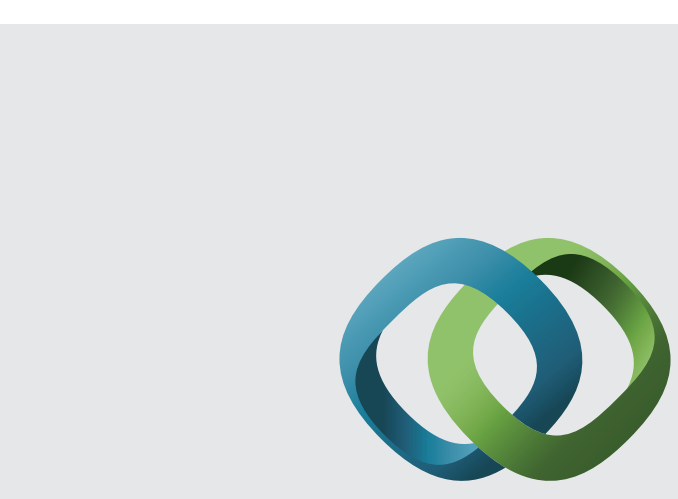

\section{Hindawi}

Submit your manuscripts at

http://www.hindawi.com
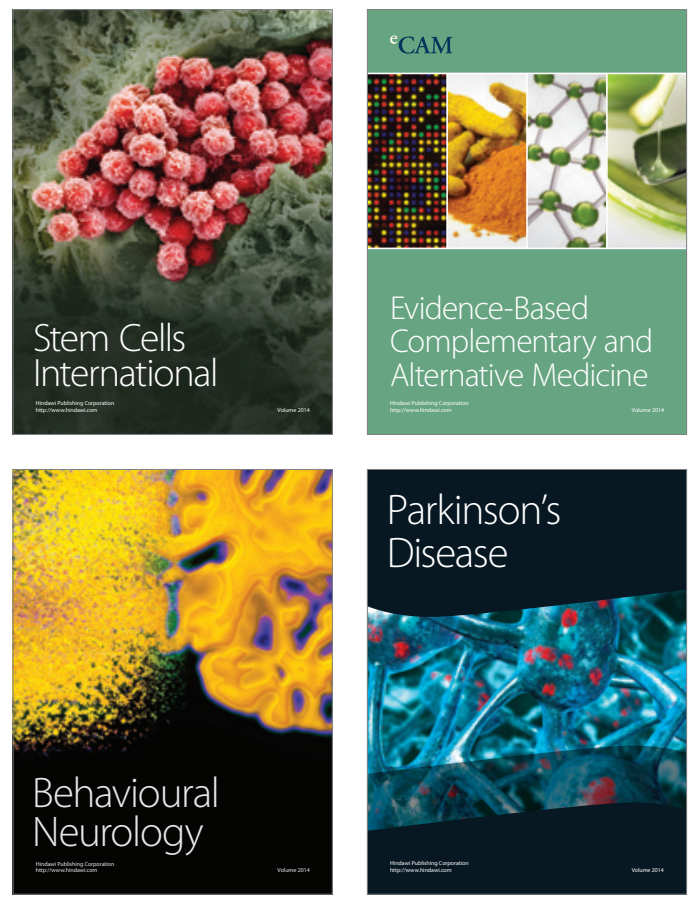
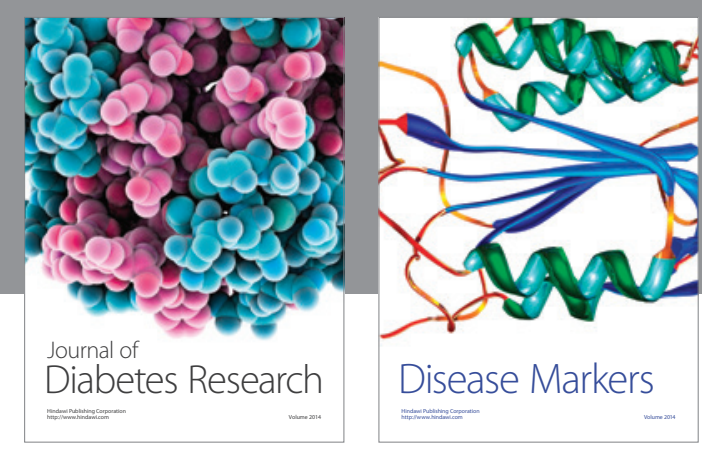

Disease Markers
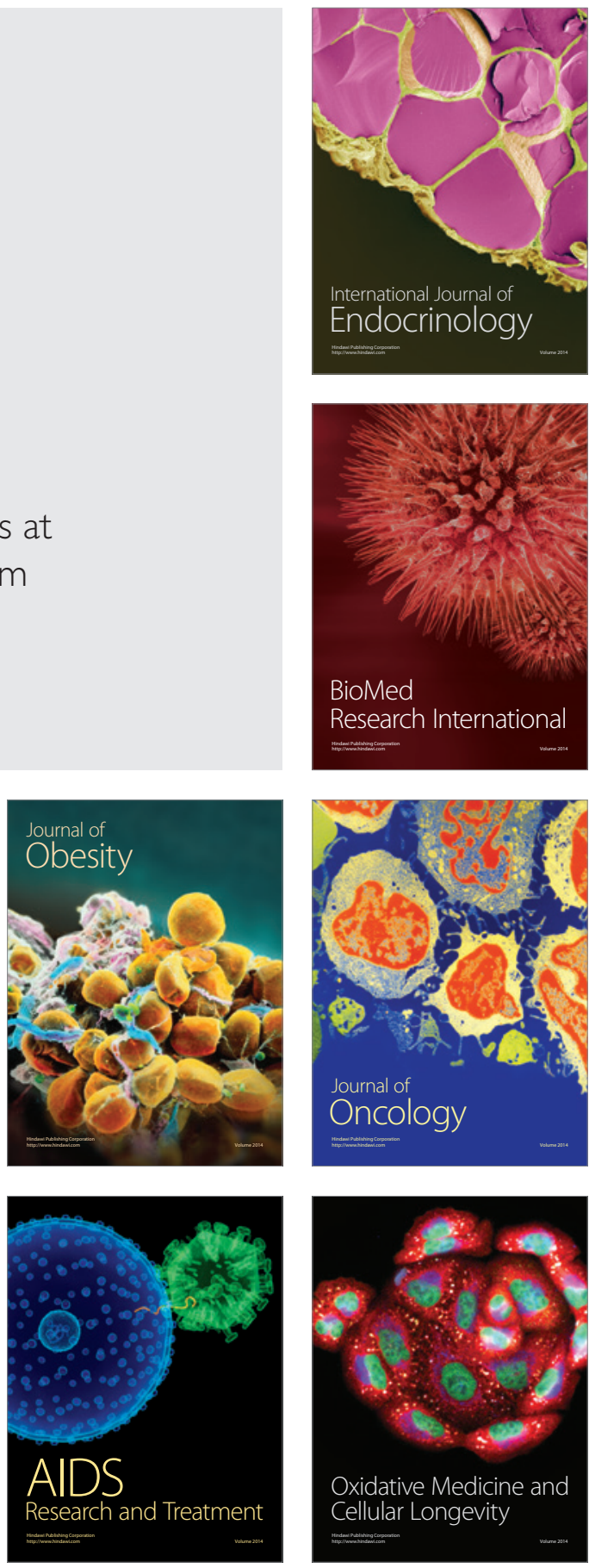